\title{
La farmacoterapia en Celso y Escribonio Largo
}

\author{
Fulgencio Martinez Saura*
}

Para conocer a fondo una civilización, entre los muchos aspectos que hay que saber están los relacionados con los medios utilizados para favorecer la salud y la curación en caso de enfermedad; es decir, sus aspectos sanitarios. Estos aspectos presentan distintas facetas que abarcan desde la arquitectura sanitaria (termas, acueductos, letrinas, etc.) hasta las perspectivas puramente terapéuticas, una de las cuales es la utilización de los remedios curativos procedentes tanto del reino vegetal, como animal o mineral por esa civilización. En el presente trabajo se ha intentado hacer una recopilación de los fármacos utilizados en la medicina romana durante la primera mitad del S.I d.C. utilizando como base los textos de Celso ${ }^{1}$ y Escribonio Largo ${ }^{2}$, lo que se ha expuesto en forma de tablas para evitar una gran extensión del texto; al mismo tiempo que se facilita la comparación y comprensión de los mismos en ambos autores. Pero antes intentaremos hacer una breve aproximación histórica al concepto de fármaco y a su desarrollo histórico.

Los métodos terapeúticos usados por los hipocráticos se diferenciaron desde el principio en las tres partes básicas del tratamiento, que perdurarán en toda la medicina occidental durante siglos de: farmacoterapia, dietética y cirugía, según que el remedio curativo empleado fuera respectivamente, el uso de los fármacos, la dieta que se basaba no sólo en el uso terapéutico de la alimentación, sino también en ciertas medidas físicas como baños, ejercicios, etc., y la cirugía basada en el tratamiento "por la mano" (Keipoupr $\alpha)$. En este trabajo, como su propio nombre indica sólo

\footnotetext{
* Instituto de Salud Carios III.

1 Como texto básico hemos utilizado "De Medicina" de A.C. CELSo, comentada por W.G. SPENCER, L.C.L., London 1971.

2 Escribonio LARGo "Compositiones" Trad. A. Marsilı, Omnia Medica, Pisa
} 
nos referiremos al uso de los fármacos, dejando para otra ocasión el tratamiento dietético y quirúrgico.

El concepto de "pharmakon" ya existe desde época homérica y Celso en la reseña histórica (la primera Historia de la Medicina que nos ha llegado), que aparece en el Prooem.,3 hace referencia a Podalirio $y$ Machaon, hijos de Asclepio que fueron con Agamenón a la Guerra de Troya, de los que Homero (II.XI, 833) dice que curaban "por medio del cuchillo y los medicamentos", únicas partes de la medicina que eran entonces conocidas. Según Plinio (N.H.XXV,11 y sig.), Homero expresa en su obra admiración por Circe, gran conocedora de las hierbas, aunque el primero en escribir sobre ellas fue Orfeo y tras él, Museo y Hesiodo. También comenta que fue Pitágoras el primero en escribir un libro sobre las propiedades de las plantas medicinales, asignando su descubrimiento a Apolo, Esculapio y otros dioses.

En su origen el término «pharmakon» significa veneno más que medicina pues se extrajo, primero de animales venenosos, y posteriormente de las plantas; en la Odisea (IV.230), por ejemplo, se menciona la unepenthe" comentando que procede de Egipto, país rico en opio y en otras plantas venenosas, y en (1.260) Ulises va a Epiro a buscar un veneno para sus flechas. En otros libros de la literatura griega aparecen, con frecuencia, referencias a los venenos como en: "Agamenón» de Sófocles, "Medea» de Eurípides, etc. El fundamento de la acción nociva de los animales ponzoñosos, según el concepto griego, se producía tanto por medio de la mirada del animal, cómo por su mordedura, digestión de sus productos, etc., pero Celso ya sabe que el veneno de las serpientes sólo es nocivo cuando estas muerden a su victima. En la Roma Imperial, el uso de venenos con fines homicidas levantó ríos de tinta, asi Séneca dice (Ep,119): "Los hijos envenenan a sus padres, las esposas a sus maridos..."; Horacio hace referencia a la bruja envenenadora Canidia (Georg.111,284), y son muchos los envenenamientos reales o imaginarios de grandes personajes de la vida romana entre ellos bastantes emperadores y altos funcionarios.

El concepto del veneno y de su doble acción, letal en dosis grandes y como contraveneno en dosis reducidas o debidamente preparado, también se encuentra frecuentemente en la literatura grecorromana, por ejemplo, el escorpión machacado y tostado se usa como contraveneno de su picadura; estas ideas están relacionadas con las doctrinas de la simpatia, homeopatía e isopatía e incluso podríamos decir actualmente que lo están también con las bases teóricas de la inmunidad o autodefensa de los tejidos y fluidos corporales contra la penetración de agentes extraños. Otras 
veces, el uso de los fármacos aparece relacionado con un conocimiento empírico de los mismos, conseguido a través de la sabiduría popular y demostrado por los éxitos conseguidos en su uso con el paso de los años, este mismo uso hará que se desaconsejen otros remedios que la práctica demuestra como ineficaces o nocivos.

En época Imperial el origen de los fármacos utilizados en la farmacopea romana era muy variado, hasta el punto de que tanto Celso como Escribonio hacen referencia al origen exótico de muchos de estos productos, en torno a los cuales se montó un complejo sistema para obtener pingües beneficios de una forma fácil falsificando y adulterando los pretendidos fármacos; esto dicen Plinio, Escribonio Largo y Galeno, que comentan la cantidad y diversidad de tratantes de fármacos que debieron de pulular por los mercados de Roma a los que acudían todos los que precisaban de algún remedio y cómo estas falsificaciones estuvieron favorecidas por la ignorancia que en general tenian los médicos sobre estos productos ya que en su mayoría tenían que asesorarse por los propios traficantes. Por ello, dirá Plinio (XXVI,16) ulas propiedades de las plantas permanecen en su mayor parte desconocidas ya que solo se han experimentado por traficantes incultos". A pesar de este panorama, también debieron de haber personas entendidas en sus efectos y de buena voluntad por ello dice $\mathrm{E}$. Largo (Comp.68,1), hay personas que... "A menudo pueden librar instantáneamente de la enfermedad, del dolor y del peligro como si fuera por intervención divina, administrando plantas eficacísimas".

Desde luego, uno de los problemas de esta época fue el desconocimiento de la química por lo que la tradición y la experimentación tuvieron que suplir estos conocimientos y ser la base de la terapéutica; todos los componentes se podían cambiar por otros más económicos con efectos más o menos parecidos, y otro problema era que muchas de las plantas usadas procedían de lugares lejanos así el incienso procedía de Arabia, el láser de Cirenáica, el licio de la India, etc., por lo cual sus precios eran muy elevados y esto también favorecía estas falsificaciones.

Con el tiempo, la mayoría de los medicamentos utilizados fueron los de naturaleza vegetal presentándose de diferentes formas como: polvos, pociones, pildoras, lociones, ungüentos, pesarios, etc. Su forma de actuar se consideró que se debía a la propia "dynamis" o «poder interno" propio del fármaco y su mecanismo de actuación se entendió de distintas maneras según los distintos autores y escuelas; así encontramos como probables mecanismos: la "agitación» de los humores, la "atracción» de estos por el medicamento, etc.

La medicina hipocrática, en un principio, no usó muchos medicamentos, sólo unos cuantos como: la tisana de cebada, hidromiel (agua con miel), 
oximiel (vinagre, agua y miel), la leche, el vino, etc., que procedían de los alimentos, además de purgantes como el eléboro, plantas diuréticas como la cebolla y el apio, etc.; en esa época los narcóticos se usaban poco y entre ellos, sobre todo la adormidera. Ackernecht y otros, consideran que el número de plantas con fines terapeúticos usadas por los hipocráticos no superaron la cifra de 250 a 263 . Otras substancias que se usaban con fines terapéuticos procedian del mundo animal como: cantáridas ${ }^{3}$, grasa animal, bilis, castoreo ${ }^{4}$, cuerno de ciervo, caracoles machacados, y otros, que en su mayoría eran conocidas desde época arcáica y, por último, remedios de origen mineral como alumbre, sal, sosa, tierras de diferentes procedencias, etc., que en un principio se usaron poco y siempre se aplicaron de forma externa, sobre todo en forma de ungüentos. De entre estos compuestos sólo se solía administrar por via oral el óxido de hierro.

Entre los autores antiguos que escribieron sobre terapeútica destaca Diocles de Caristo (S.IV a.C.) que escribió el primer tratado griego sobre hierbas, "Rhizotomiká", asi como otros sobre fármacos y venenos que no nos han llegado, aunque sabemos que influyeron poderosamente en autores posteriores.

Teofrasto (370-287 a.C.) que no era médico, escribió un amplio tratado sobre botánica en el que además incluyó datos folclóricos; en época de Erasístrato un tal Apolodoro escribió sobre venenos, y Andreas de Caristo (245-225 a.C.) de la escuela de Herófilo y médico de Ptolomeo Philopator fue el primero en escribir sobre la rabia llegando a ser una autoridad en farmacología; pero desgraciadamente tampoco nos ha llegado ningún escrito suyo.

En época helenística, aumentó mucho el número de fármacos utilizados y además se produjo un cambio de interpretación en su forma de actuar, así, para Herófilo, los fármacos son «las manos de dios" y Plinio comenta de él (N.H.XXV, 15) que llegó a decir que ciertas plantas tenían efectos beneficiosos, incluso, cuando se pisaban al caminar. Los empíricos utilizaron la polifarmacia y otros seguidores de esta escuela como Dionisio de Apamea, Zenón, Filoxeno, etc., escribieron diversos listados de fármacos. Con Asclepiades (S. 1 a.C.) y sus seguidores, se buscó un retorno a los medicamentos de origen popular y a su trasfondo de superstición, a

\footnotetext{
3 La cantárida es un insecto coleóptero que machacado posee propiedades vesicantes si se aplica de forma tópica y al que ingerido se le atribuyeron propiedades afrodisiacas

4 El castoreo, en su origen, era una substancia segregada por las glándulas abdominales que poseen los castores y que se usó mucho en medicina al atribuirsele diferentes propiedades terapéuticas, entre ellas las antiespasmódicas.
} 
pesar de que la actitud del maestro fue casi siempre reducir la farmacopea lo más posible, sustituyéndola por la fisioterapia y los enemas, mucho menos agresivos.

Desde mediados del siglo II a.de C., tuvo gran auge el estudio de los venenos por autores como Nicandro de Colofón que dedicó un poema, "Theriaka", a los remedios recomendados contra la mordedura de animales ponzoñosos, y otro, "Alexipharmaka", a los venenos en general; otro personaje, el rey del Ponto, Mitridates, cultivaba en sus jardines hierbas ponzoñosas para estudiar experimentalmente sus efectos y basándose en estos elaborar los pertinentes antídotos; alguno de los cuales, llegaron a ser famosos hasta la Edad Media. Crateuas, médico de la corte de Mitridates IV Eupator (120-63 a.C) escribió un libro: "Rhizotomicon" del que nos han llegado algunos fragmentos a través de las obras de Dioscórides, de Plinio y de Galeno. También Heráclides de Tarento (S.I a.C), según Galeno, escribió sobre la theriaca y los animales venenosos y se cree que tanto Plinio como Celso se inspiraron en su obra para escribir sobre estos temas.

En Roma, la penetración de la medicina y de los médicos griegos, hizo que se substituyeran paulatinamente los medicamentos tradicionales, como los que menciona Catón, granada, col, lana, hinojo, etc., (para BOSCHERINI ${ }^{5}$ muestra una indudable influencia griega no solo en cuanto a la terminología utilizada, sino en las diferencias que hace con respecto a las patologías que son las habituales en los libros de medicina griegos), por los que recomendaban los médicos griegos, que fueron aumentando su farmacopea con los remedios que llegarán a la gran urbe importados de todos los paises conquistados por sus ejercitos, con este motivo, la farmacología romana se ampliará de forma acelerada, dando cabida a múltiples remedios exóticos procedentes de todos los rincones del Imperio, que como hemos comentado, frecuentemente eran falsificados, pero que en términos generales, abrió las puertas a un importante comercio de estos productos.

Asi está la situación cuando Celso, Escribonio y, más tarde, Plinio y Dioscórides de Anazarba escriben sus tratados. En el prólogo del Libro V, Celso, hace referencia a las enfermedades que se tratan con medicamentos, y también a la importancia concedida a estos por escuelas médicas como la Empírica, los médicos helenísticos etc.

\footnotetext{
Welt.

BoscherinI S., La Medicina in Catone e Varrone en Aufstieg und Niedergang der Römischen
} 
En el libro hace una relación de los «Medicamentos sencillos», clasificándolos según su efecto que la mayor cantidad de las veces se basa en su acción tópica y con menor frecuencia en sus acciones generales; cosa lógica ya que en la mayoría de los casos la acción local es mucho más evidente que una más o menos hipotética acción "general". Posteriormente hace una descripción de las posibles mezclas de medicamentos y de su presentación en forma de píldoras, ungüentos, pastillas, pesarios, etc., y luego, amplia las descripciones farmacológicas al tratar de cada una de las enfermedades, asi, al hablar de las enfermedades de los ojos (en el Libro VI), cita la composición de multitud de colirios y de otros preparados. Aunque la inmensa mayoria de los medicamentos descritos por Celso ya eran conocidos en épocas anteriores, no por ello deja de tener importancia su labor compiladora asi como la sistemátización que realiza de acuerdo con sus efectos y no segun su naturaleza u origen.

En los medicamentos descritos a veces nos encontramos que es dificil identificar a que se refiere Celso en concreto, ya que en muchos casos el mismo término puede designar a dos o mas compuestos que nada tienen que ver entre sí en otros casos la palabra usada se dejó de utilizar hace mucho tiempo con lo que actualmente se ha perdido su significado, y por último, otras veces, el medicamento designado hace referencia a algún producto que era «importado» a Roma desde algún punto del Imperio y que posteriormente dejó de utilizarse en la farmacopea occidental cuando desapareció el poder de Roma; por todo esto rogamos que el lector sea benigno con nuestro intento de asimilar los productos que se citan a sus equivalentes actuales.

El otro gran autor romano que en el S.Id.C. trató la farmacología fue Escribonio Largo cuya obra "Compositiones" es el primer tratado farmacológico escrito (entre el 44 y el 48) en latín. Las fuentes utilizadas proceden tanto de los médicos clásicos que le precedieron desde Hipócrates como de autores romanos: Celso, Meges, Euelpisto, etc., y también menciona como fuentes a personajes relacionados con el curanderismo como una tal Favila (Comp.122) "Hoc medicamento muliercula quaedam ex Africa Romae multos remediavit». Su actitud es la de un profundo respeto por la experimentación directa con los fármacos, así como por un reconocimiento por los que tienen un origen popular; también insiste en la precisión de la dosis que se ha de utilizar, la escrupulosidad en la preparación del fármaco y su pureza, denunciando todo uso doloso de los mismos por los que él denomina como: pigmentarii, unguentarii, pharmacopolae y seplasiarii.

Escribonio, fue un ecléctico en medicina, lo mismo que Celso, teniendo ambos una mentalidad práctica aunque Escribonio presenta mayores afanes 
investigadores pero sin dejar de utilizar todo lo que la tradición o la experiencia le aconseja que puede ser útil en el tratamiento de las enfermedades. Sus "Recetas", aparecen descritas siguiendo el tradicional orden anatómico desde cabeza a pies, con 271 recetas que en su mayoría son compuestas de bastante número de fármacos. El uso de elementos im. portados de la medicina mágica o popular es mayor en Escribonio que en Celso, aunque nunca tanto como en Plinio, e incluso, no duda en comprar las fórmulas medicamentosas a curanderos como él mismo comenta con relación al célebre medicamento para el cólico adquirido a Favila.

En cuanto a los autores posteriores, Dioscórides de Anazarba (c. 65 d.c. ) escribe su "Materia Médica", casi totalmente desprovista de elementos populares y supersticiosos y aunque es casi contemporánea de la Historia Natural de Plinio, en esta aún estan presentes todos los aspectos retrógrados de la farmacopea tradicional romana. En la obra de Dioscórides desaparece la visión hipocrática de la "vis medicatrix naturae" llegándose a afirmar, por el contrario, que la Naturaleza no es que no ayude a la curación del enfermo, sino que suele perjudicar, con lo que se facilitará la postura intervencionista de los médicos. Dioscórides en su obra recoge gran parte de las tradiciones y ceremoniales usados en la recogida y preparación de las plantas medicinales. De las plantas tratadas solo proceden ocho de Italia, cuatro de España (una de Baleares) y dos de Galia pero ninguna de los países situados al norte del Danubio con la única excepción de dos de las Islas Británicas. Su libro, en cinco tomos (mas un sexto dedicado a tóxicos), describe medicamentos de origen vegetal, animal y mineral, con alrededor de 4.700 usos medicinales en 360 variedades de acción terapéutica (laxantes suaves, laxantes fuertes, analgésicos, etc.) y es el resultado de muchos viajes en los que se informó a traves de la gente que conoció sobre los efectos de las plantas medicinales, además experimentó por si mismo en muchas ocasiones dichos efectos. Dioscórides no se relacionó con ninguna secta médica y atacó a Asclepiades por su falta de atención a las propiedades reales de los fármacos. La estructura del libro es de tal forma que dedica un capítulo a cada planta al comienzo del cual hay un dibujo de la misma con su raíz, tallo, fruto, etc., coloca el nombre "nativo" griego o latino o, incluso a veces, en sirio, comenta el hábitat natural de la planta, sus propiedades y efectos terapéuticos para acabar hablando de los efectos colaterales, los datos de recolección, almacenamienmto, métodos de preparación y probables adulteraciones.

En cuanto a Plinio, este, distingue tres tipos de escritos medico-botánicos y los clasifica en: aquéllos que estudian las plantas, otros en los que se describen sus virtudes medicamentosas (como los de Dioscórides), y 
en tercer lugar simples listas en las que solo se citan las plantas. Este mismo autor, al hacer referencia a las obras escritas por romanos sobre plantas medicinales dice (XXV,4 sig.), que el primer romano que escribió sobre ellas fue Catón, luego Pompeyo Lenaeus (un liberto de Pompeyo Magno) y tras él Gayo Valgo que dejó inacabada una obra que había dedicado al emperador Augusto. Por último, considera a Antonio Castor como «la mayor autoridad botánica de nuestro tiempo", y comenta (XXV, 9) que le enseñó a él sus jardines en los que crecian multitud de plantas que él cuidaba personalmente a pesar de tener cerca de cien años de edad.

Otro autor romano que trató el tema fue Sextius Niger, que escribió una "Materia médica" a mediados del S. I d. C, que contribuyó mucho a la obra de Plinio.

En el presente trabajo hemos creído conveniente hacer un estudio en profundidad de los fármacos utilizados tanto por Celso como por Escribonio, descartando las referencias de Plinio y Dioscórides ya que estos dos últimos autores adolecen, el primero de una falta total tanto de actitud crítica como de experiencia médica, haciendo solo una recopilación de "posibles» fármacos, y el segundo porque supone un paso tan grande en la descripción de los fármacos que no es comparable a los dos autores que aquí tratamos, siendo necesario dedicarle en exclusiva más de un trabajo de análisis y recopilación de sus trabajos como el tradicional realizado por el insigne médico $A$. Laguna en el siglos $X V I^{6}$.

En la relación de fármacos que aparecen en las tablas anejas se han clasificado los medicamentos simples segun su origen vegetal, mineral o animal como veremos:

\section{Medicamentos de Origen Vegetal}

Celso y Escribonio, en sus obras citan una gran cantidad de plantas diferentes usadas con fines medicinales; su utilización es tanto a partir de sus hojas como de otras partes de ella: raices, tallos, resinas, gomas, etc., y en cuanto a la preparación farmacéutica puede ser decocciones, jugo en fresco, infusiones, etc., aunque en otras ocasiones se usan productos más elaborados como pueden ser el vino, aceite o vinagre. Sus efectos terapeúticos

6 Dioscorides de Anazarba. Trad. A. Laguna (1955), Instituto de España. Madrid 1968 (prolog. y coment. T. HERNANDO). 
son muy variados lo mismo que su forma de utilización, que puede variar desde un emplasto hasta la mera colocación de la planta "bajo la almohada», como en el caso de la mandrágora para "conciliar el sueño» (Med. $3,18,12)$.

En la tabla de los fármacos de origen vegetal que damos a continuación, hemos hecho constar: el nombre vulgar de la planta en castellano, su nombre científico, el nombre atribuido por Celso, lo mismo en Escribonio, y el uso terapeútico concedido por ambos. Se ha prescindido de comentar los efectos terapéuticos de aquellos elementos que forman parte habitual de la dieta como: vino, miel, derivados lácteos, pan, etc., pues estos merecen un trabajo monográfico y exclusivo para ellos.

En relación con estas tablas, hemos de hacer algunas observaciones, así, Celso, no menciona para nada a la amapola negra (Papaver somniferum) de la que se extrae el opio y que si cita Escribonio con mucha frecuencia, a pesar de ser muchos los autores que opinan que el primero en hablar de ella fue Dioscórides (IV,66 y VI,17). Otra planta, la "cassia», para Spencer es semejante a la canela, para Dioscórides $(I, 12)$, es tambien un tipo de esta, y tanto Celso cómo Escribonio diferencian varios tipos de ella, negra (Comp.177,269), daphnitides (Comp. 269) y rosa (Comp. 70) y Celso solo habla de la cassia «normal» y de la negra $(5,23$, B y $5,23,2)$. Creemos que la cassia corresponde a la Cassia angustifolia, en tanto que la daphnitides sería lo que vulgarmente conocemos como "laureola», en tanto que la cassia negra y la rosa serian variedades de la $\mathrm{C}$. angustifolia.

Para Spencer, el "hissopus" sería una planta no identificada, pero creemos que Laguna $(I I, 28)$ tiene razón al afirmar que corresponde a nuestro hisopo. En cuanto a las almendras, aparecen mencionadas por Celso como nux Graeca la almendra dulce y nux amara la almendra amarga, en tanto que Escribonio a esta última la denomina amygdalus amara. Por último, los denominados por Celso iuncus, corresponden a plantas de la familia del Cyperus, una de ellas es la $C$. sculentus que es nuestra popular "chufa».

Por último, para facilitar la comprensión de los términos usados en la columna de efectos terapéuticos, resumimos, a continuación, la definición terminológica de estos efectos farmacológicos:

Analgésico: Que calma el dolor

Antidisnéico: Facilita la respiración

Antiinflamatorio: Disminuye la inflamación

Antipirético: Baja la fiebre

Astringente: Constriñe los conductos corporales (vasos, intestino, etc.)

Atractivo: Facilita la extracción de cuerpos extraños 
Béquico o Antitusígeno: Calma la tos

Carminativo: Elimina los gases del aparato digestivo

Cáustico: Que quema

Corrosivo: Que corroe

Detersivo: Limpia o purifica

Diaforético: Provoca la sudoración

Diurético: Facilita la eliminación de orina

Emoliente: Ablanda tumores y furúnculos

Epispástico: Atrae los humores al exterior

Erosivo: Produce erosión en la piel

Escarificante: Produce escaras

Escarizante: Hace caer las escaras

Espasmolítico: Suprime espasmos viscerales

Hemostático: Detiene la fluxión de sangre

Madurativo: Madura los focos de pus

Narcótico o Somnífero: Favorece la aparición de sueño

Refrescante: Baja el calor febril y disminuye la sed

Repercusivo: Hace retroceder los humores

Resolutivo: Favorece la resolución de humores

Rubefaciente: Provoca rubicundez en la piel

Suavizante: Elimina asperezas

Tónico: Tonifica el organismo

Ulcerativo: Provoca la aparición de úlceras

Vesicante: Produce ampollas en la piel

Vulnerario: Cura y cicatriza llagas, úlceras y heridas

\section{Medicamentos de origen Mineral}

En la relación de medicamentos de origen mineral, hemos encontrado dificultades en el reconocimiento de alguno de los productos citados por Celso y Escribonio, ya que no siempre ha sido fácil identificar con certeza a qué producto se podian estar refiriendo; en otros casos ha sido posible reconocerlo gracias a la obra de Plinio, así, en relación con la Piedra Asiana y la Piedra Sarcófaga, Plinio la define como una piedra procedente de Assos (en Tróade), que es capaz de consumir en cuarenta dias los cadáveres encerrados en sarcófagos fabricados con ella (N.H.XXXVI,132), esta piedra corresponde geológicamente a una roca de naturaleza volcánica no bién definida.

En relación con la Piedra Frigia, también Plinio (N.H. XXXVI,143-144) la define como una piedra porosa que una vez mojada en vino y luego quemada se usa con fines medicinales. 
Con relación a la Hematita, Plinio (XXXVI,144sig.), la relaciona con la magnetita, el esquisto, etc., citando hasta cinco tipos diferentes de hematita; nosotros creemos que Celso se refiere al mineral de hierro que en Plinio es la "hematita de Etiopía» que él refiere a un tal Sótaco, y que actualmente sabemos que es un óxido de hierro.

El "Psórico", lo describe Celso en (6.6,31B), al mencionar los colirios y lo define como:

"una mezcla de calcitis y cadmia que se machacan y mezclan con el doble de vinagre. Esta preparación se pone en una jarra de barro tapada con hojas de higuera y se deja bajo tierra durante veinte dias, al cabo de los cúales se saca de la tierra y'su contenido se tritura de nuevo y toma el nombre de psórico".

Por lo tanto es una fórmula magistral relacionada con el poder telúrico y cuyo origen ignoramos. En relación con el mineral que tanto Celso cómo Escribonio denominan "misy", ignoramos a que mineral corresponde y distintos autores modernos lo han relacionado con el "vitriolo", el "stibium" (Spencer), etc. En el Dioscórides de Laguna $(V, 75)$, se dice que es semejante al oro en su color, opinando Laguna que: "la calcitis, el misy, la melanteria y el sori son minerales del mismo linaje y difieren poco en sus facultades". Por lo tanto, siendo los otros minerales de cobre, es lógico pensar que el misy sería un mineral de este metal que no podemos concretar.

Curiosa relación, es la del hierro y el "agua de herrería" que se basa en que el agua contenida en la vasija de barro en la que se introducia el hierro al rojo para que fraguara, se creía que tenía el poder de reducir el bazo ya que los animales criados en las herrerías tenían pequeña esta viscera. Acaso esta relación tuviera algo que ver con la anemia ferropénica, pués está demostrado que en un $10 \%$ de casos dicha anemia cursa con una hipertrofia del bazo, esta relacion que puede parecer casual puede que tenga alguna base real sobre ciertas afecciones, más allá de la mera casualidad, debida a un conocimiento empírico de enfermedad-curación que está por encima del azar.

\section{Medicamentos de origen Animal}

Para terminar con esta relación de medicamentos "simples" en las obras de Celso y Escribonio, también exponemos los de origen animal, así como los efectos que tienen, según ellos, en el organismo.

Plinio, comenta en sus Libros XXVIII y XXIX, gran parte de estos medicamentos de origen animal, y entre ellos: saliva, leche, cabellos, cenizas 
de heces, orina de niño, etc. De la leche de mujer dice que es la más dulce y delicada de todas, de gran utilidad en fiebres prolongadas, traumatismos oculares, etc. La grasa de león, la recomienda Plinio en: alteraciones de la complexión, fiebres cotidianas y traumatismos articulares. En relación con la sangre, dice Plinio que la de caballo y yegua tienen poder corrosivo, si bien no la tienen la de los animales vírgenes. De la lana, dice que en la antigua Roma se le concedian poderes sobrenaturales, de ahi la costumbre de tocar con ella los goznes de las casas nuevas para que tuvieran buenos augurios, y además era utilizada en dislocaciones, como cicatrizante y en otras enfermedades.

Como veremos, fueron muchos los medicamentos usados en la Roma del siglo 1 lo que se debió, en gran parte, a haberse producido una simbiosis entre los medicamentos de origen popular y los de procedencia "científica" de la medicina griega y alejandrina. También, como hemos comentado tanto Celso como Escribonio, al describir los diferentes medicamentos hacen una relación mucho más científica y estricta que la de Plinio, basándose más en descripciones de profesionales de la medicina, que como aquél, cuyas descripciones dan cabida a la magia, la fabulación, etc. y proceden de diferentes fuentes más "literarias" y menos "profesionales» que las de nuestros autores.

En este trabajo hemos intentado no sólo exponer de forma clara y resumida los conceptos de Celso y Escribonio sobre esta parte de la medicina, sino además, hacer una relación de los medicamentos utilizados en su época. Hemos de recordar que tras escribir sus obras aparecieron en el mundo romano varios tratados sobre medicamentos entre los que hay que destacar la de Dioscórides que supuso la culminación de la farmacología en Roma. De entre la multitud de fármacos de origen vegetal citados, actualmente persiste el uso de algunos como: aceite de oliva, de almendras, de cereales, etc., que se usan aún como emolientes y vehículos de otros medicamentos; la goma arábiga como emulsificante y vehículo, la de tragacanto como demulcente en medicamentos de aplicación dérmica u oral; el aceite de castor, que actualmente se extrae de la semilla del Ricinus comunis y se usa como protector mecánico, el ácido tánico extraído de las agallas de roble que se usa como hemostático absorbible, el camfor y la mostaza como irritantes igual que entonces; el aceite vegetal, metilcelulosa, psylliu (plantago), goma de tragacanto, salvado, casia (Cassia angustifolia) y aloe, como laxantes y catárticos; y por último, hemos de recordar que la salicina de la que por hidrólisis se extrae el ácido salicilico precursor del ácido acetil-salicílico (Aspirina) se extrae de la corteza del sauce (Salix alba). 
De entre los medicamentos de origen mineral todavia se usan: talco, óxido de zinc, ácido bórico, etc., como polvos protectores y secantes; las sales de bismuto, trisilicato magnésico, hidróxido de aluminio, carbón, etc., como adsorbentes y protectores intestinales; las sales de aluminio (cloruros, sulfatos, etc.) como antiperspirantes; el alumbre como cáustico; la creta como antiácido digestivo; las sales de magnesio (magnesia) de sodio y potasio como catárticos; la violeta de genciana, azufre, etc., como antisépticos y desinfectantes, y por último, metales como: arsénico (cáustico), antimonio (cáustico, emético, expectorante), plata (cáustico, corrosivo, astringente, cicatrizante), hierro (antianémico), etc., etc.

Entre los medicamentos de origen animal se usan aun la lanolina como base de pomadas y detersivo, las ceras como bases, la cantárida como vesicante, extractos de bilis bovina como colagogos, etc.

En lo relativo a las formas y compuestos medicamentosos la mayoría de ellos eran de aplicación tópica externa, aunque también había enemas, píldoras, purgantes, jarabes, pesarios, pastillas, polvos, emplastos. Y desde luego, los colirios sólidos con sus marcas de fabricante, forma de uso, etc., marcados en su superficie.

Por último y a continuación, ofrecemos al lector la relación, por orden alfabético, de los distintos fármacos esperando que le puedan ser útiles en futuros trabajos sobre estos temas, pero antes hemos de hacer referencia al cuadro de medicamentos que aparecen en la traducción de «De Medicina" por Spencer que nos ha sido tan útil, a pesar de que en bastantes ocasiones no estamos de acuerdo con lo expuesto por su autor.

\section{BIBLIOGRAFIA}

ANORE J.: Etre Medicin à Rome. Les Belles Letres. Paris 1987

Capitani U.: Celso, escribonio Largo, Plinio il Vecchio e il loro attegiamento nei confronti de la medicina popolare. MAIA, XXIV, 1972

CATO AND VARAO: On Agricultura. L.C.L. London.

Celsus: De Medicina. Translated by W.G. Spencer. vol. Loeb Classical Library (L.C.L.). London, 1971.

Dioscórides de Anazarba: Trad. Andrés Laguna (1955). Instituto de España. Madrid 1968. Comentada por T. Hernando.

Escribonio LaRgo: Compositiones. Trad. A. Marsili. Omnia Medica. Pisa.

Grmek M.D.: Storia del Pensiero Medico Occidentale. 1 Antichita e Medioevo. Laterza. RomaBari 1993.

Homero: La lliada, Gredos, Madrid 1991.

LaIn Entralgo: Historia Universal de la Medicina. Salvat. Barcelona 1972.

Martinez Saura F.: Frontón, la enfermedad en el siglo Ul. Gerion, 12, 1994. pp 64-72.

Pliny, Natural History. Trans. by H. Rackham. L.C.L., London 1969.

SCARBofough J.: Roman Medicine. Thames and Hudson London 1969.

Tratados Hipocráticos. Trad. C. García Gual y otros. Gredos, Madrid, 1990. 
FÁRMACOS ORIGEN VEGETAL

\begin{tabular}{|c|c|c|c|c|}
\hline Español & Cientifico & En Celso & En Escribonio & Indicaciones \\
\hline Abeto rojo (resina) & Picea excelsa & - & $\begin{array}{l}\text { Pituinus 201, 202, 205, } \\
214,215,263\end{array}$ & $\begin{array}{l}\text { Antinflamatorio, } \\
\text { Cicatrizante }\end{array}$ \\
\hline Abrótano & $\begin{array}{l}\text { Artemisia } \\
\text { abrotanum }\end{array}$ & $\begin{array}{l}\text { Abrotanum } 3,21,7 / 4, \\
8,3 / 5,5,2 / 5,11 / 5,18.35\end{array}$ & Abrotanum 78, 188 & $\begin{array}{l}\text { Antidisnéico } \\
\text { Anditodo (Acónito), } \\
\text { Diurético, }\end{array}$ \\
\hline Absenta o ajenjo & $\begin{array}{l}\text { Artemisia } \\
\text { absinthium }\end{array}$ & $\begin{array}{l}\text { Absinthium } 3,21,6 / 3 \text {, } \\
24,2 / 4,7,3 / 4,12,2 / 4 \text {, } \\
15,3 / 4,16,2 / 4,24,2 /\end{array}$ & Absinthium 192 & $\begin{array}{l}\text { Antidiarreico, } \\
\text { Hemostático } \\
\text { Antídoto }\end{array}$ \\
\hline Acacia (goma) & Acacia Arabiga & $\begin{array}{l}\text { Acacia } 4,25,2 / 5,1 / 5,7 / \\
5,20,5 / 5,23,3 / 6,6,11 / \\
\text { etc. }\end{array}$ & $\begin{array}{l}\text { Acacia } 23,41,113, \\
115,142,170,247, \\
248,256\end{array}$ & $\begin{array}{l}\text { Antidiarréico, } \\
\text { Hemostático } \\
\text { Antiinflamatorio }\end{array}$ \\
\hline $\begin{array}{l}\text { Acebuche } u \text { olivo } \\
\text { silvestre }\end{array}$ & Olea oleaster & - & Oleaster 62,114 & $\begin{array}{l}\text { Cáustico, En Cáncer } \\
\text { de boca e instestino }\end{array}$ \\
\hline Acedera común & Rhumex acetosa & $\begin{array}{l}\text { Lapatium 2,21/2,29, } \\
1 / 3,6,14 /\end{array}$ & Lapathum $57,127,253$ & $\begin{array}{l}\text { Ictericia, } \\
\text { Antisarnoso, } \\
\text { En Fiebres }\end{array}$ \\
\hline Acelga & Beta vulgaris & $\begin{array}{l}\text { Beta } 3,24,2 / 4,16,2 / \\
5,27,13 \mathrm{~A}\end{array}$ & Beta 7 & $\begin{array}{l}\text { Analgésico, } \\
\text { Cicatrizante, } \\
\text { Quemaduras }\end{array}$ \\
\hline Acónito & Aconitum napellus & - & Aconitum 188 & Tóxico \\
\hline $\begin{array}{l}\text { Acoro o Cálamo de } \\
\text { Alejandría }\end{array}$ & Acorus calamus & $\begin{array}{l}\text { Acorus, Calamus } \\
\text { Alexandrinus } 3,21,7 / \\
5,23,1 \mathrm{~B} / 5,23,31 / 5 \\
24,1 /\end{array}$ & $\begin{array}{l}\text { Acorus 121, 126, 170, } \\
176,177,269\end{array}$ & $\begin{array}{l}\text { Antidoto, } \\
\text { Analgésico, } \\
\text { Diurético }\end{array}$ \\
\hline Adelia & Nerium oleander & - & Rododaphne 55 & Analgésico dental \\
\hline Agalla (nuez de) & \begin{tabular}{|l} 
Quercus \\
lusitanicus \\
Orient. infect.
\end{tabular} & $\begin{array}{l}\text { Galla } 5,5,2 / 5,6 / 5,7 / \\
5,16 / 5,18,1 / 5,20,1 / \\
5,20,4 / 5.22 .1 / 5,22,21 /\end{array}$ & $\begin{array}{l}\text { Vel gallae } 4,31,61,63 \\
65,70,71,81,113,208 \\
248,256\end{array}$ & $\begin{array}{l}\text { Erosivo, Detersivo } \\
\text { Cicatrizante, Limpia } \\
\text { la piel }\end{array}$ \\
\hline Agárico & $\begin{array}{l}\text { Polyporus } \\
\text { officinalis }\end{array}$ & - & Agaricus 106, 177 & $\begin{array}{l}\text { Antidoto, } \\
\text { Espasmolitico } \\
\text { intestinal }\end{array}$ \\
\hline Agnocastaño & $\begin{array}{l}\text { Vitex } \\
\text { agnucastus }\end{array}$ & - & Agnus 2 & $\begin{array}{l}\text { Analgésico en } \\
\text { celaleas }\end{array}$ \\
\hline $\begin{array}{l}\text { Ajedrea, Conila } 0 \\
\text { Satureia }\end{array}$ & \begin{tabular}{|l|} 
Satureia \\
montana
\end{tabular} & $\begin{array}{l}\text { Satureia } 4,15,3 / 4,16,3 / \\
4,27,1 \mathrm{D} / 5,27,8 /\end{array}$ & Cunila 124 & $\begin{array}{l}\text { Antidoto (mord. } \\
\text { serp.), Ent. higado } \\
\text { y bazo } \\
\end{array}$ \\
\hline Ajo & Alium sativum & \begin{tabular}{|l|} 
Alium $3,12,4 / 3,22,11 /$ \\
$4,4 / 4,10,3 / 4,24,1 /$ \\
$4,24,2 / 5,6,2 / 5,8 /$ \\
\end{tabular} & Alium $140,174,231$ & $\begin{array}{l}\text { Antipirético, } \\
\text { Erosivo, } \\
\text { Madurativo } \\
\end{array}$ \\
\hline Alamo blanco & Populus alba & Populus $6,9,21$ & - & Analgésico dental \\
\hline Albahaca & $\begin{array}{l}\text { Ocimum } \\
\text { basilicum }\end{array}$ & Occimum $3,22,11$ & Occimum 192 & En fiebres, Diuretico \\
\hline Alcaparra & $\begin{array}{l}\text { Capparis } \\
\text { spinosa }\end{array}$ & $\begin{array}{l}\text { Capparris } 4,8,3 / 4,16,41 \\
5,18,21 /\end{array}$ & Capparris 129, 261 & $\begin{array}{l}\text { Entermedades del } \\
\text { bazo }\end{array}$ \\
\hline Algarrobo o Yero & Ceratonia siliqua & Siliqua & Siliqua 121 & En cólico \\
\hline Aligustre o Alheña & $\begin{array}{l}\text { Ligustrum } \\
\text { sempervirens }\end{array}$ & $\begin{array}{l}\text { Ligustrum o Cyprus } \\
2,33,4 / 5,7 / 6,13,3 /\end{array}$ & - & \begin{tabular}{|l|} 
Refrescante, \\
Repercusivo
\end{tabular} \\
\hline
\end{tabular}


FÁRMACOS ORIGEN VEGETAL (Continuación)

\begin{tabular}{|c|c|c|c|c|}
\hline Español & Cientifico & En Celso & En Escribonio & Indicaciones \\
\hline Almendro & $\begin{array}{l}\text { Prunus } \\
\text { amygdalus } \\
\text { dulcis, amara }\end{array}$ & $\begin{array}{l}\text { Nux amara } 2,33,4 / \\
3,10,2 / 3,21,7 / 3,24,2 / \\
4,9,2 / 4,10,1 / 5,22,2 \mathrm{~A}\end{array}$ & $\begin{array}{l}\text { Amygdalus dulcis, } \\
\text { amara } 5,174,148 \\
\text { Nux amara } 3\end{array}$ & $\begin{array}{l}\text { Analgésico } \\
\text { Emoliente, } \\
\text { Corrosivo suave }\end{array}$ \\
\hline Aloe & Aloe soccotrina & $\begin{array}{l}\text { Aloe } 5,1 / 5,20,2 / 5,22 \\
2 \mathrm{~B} / 5,22,31 / 5,28,3 \mathrm{D} / 6,6 \\
5 \mathrm{~B} / 6,6,6 / 6,6,8 / 6,6,24 /\end{array}$ & $\begin{array}{l}\text { Aloes Indica } 21,23,31 \\
63,110,113,115,135 \\
137,139,140,158,206\end{array}$ & $\begin{array}{l}\text { Hemostático, } \\
\text { Emoliente, } \\
\text { Cicatrizante }\end{array}$ \\
\hline Alpechin o Amurca & $\begin{array}{l}\text { Liquido de las } \\
\text { aceitunas }\end{array}$ & $\begin{array}{l}\text { Amurca } 6,8,1 \mathrm{C} / 6,18 \\
2 \mathrm{C} / 6,19,1 /\end{array}$ & - & $\begin{array}{l}\text { Antiinflamatorio, } \\
\text { Cicatrizante }\end{array}$ \\
\hline $\begin{array}{l}\text { Alquequenje o } \\
\text { Halicacabo }\end{array}$ & $\begin{array}{l}\text { Physalis } \\
\text { alkekengi }\end{array}$ & $\begin{array}{l}\text { Haliccabus (entre } \\
\text { solanos) } 5,20,41\end{array}$ & - & $\begin{array}{l}\text { Antijnflamatorio, } \\
\text { Erosivo }\end{array}$ \\
\hline $\begin{array}{l}\text { Alsine u Oreja de } \\
\text { Ratón }\end{array}$ & Stellaria media & - & Auricula murina 153 & $\begin{array}{l}\text { En Eniermedad de } \\
\text { la piedra }\end{array}$ \\
\hline Altercum & Ver Beleño & & & \\
\hline $\begin{array}{l}\text { Altramuz, } \mathrm{H} \text {. } \\
\text { Lobera o Lupinus }\end{array}$ & Lupinus album & $\begin{array}{l}\text { Lupinus } 4,24,1 / 4,24,21 \\
5,28,6 \mathrm{Cl}\end{array}$ & Lupinus 144 & $\begin{array}{l}\text { Sarna, } \\
\text { Vermifugo, } \\
\text { Unidad de dosis } \\
\end{array}$ \\
\hline $\begin{array}{l}\text { Amapola espinosa } \\
\text { o Argemone }\end{array}$ & $\begin{array}{l}\text { Papaver } \\
\text { argemone }\end{array}$ & Argemonia $5,27,10 /$ & - & $\begin{array}{l}\text { Antidoto mord. } \\
\text { serp. }\end{array}$ \\
\hline Amapola negra & $\begin{array}{l}\text { Papaver } \\
\text { somniterum } \\
\text { nigrum }\end{array}$ & - & Papaver nigri 148 & $\begin{array}{l}\text { Analgésico, } \\
\text { Antiinflamatorio }\end{array}$ \\
\hline $\begin{array}{l}\text { Amapola negra, } \\
\text { Meconio }\end{array}$ & & - & Opio (bebido) 180 & Tóxico \\
\hline $\begin{array}{l}\text { Amapola negra, } \\
\text { Opio }\end{array}$ & & - & $\begin{array}{l}\text { Opio } 21,22,23,30,31 \\
32,52,77,85,86,87 \\
88,89,90,91,92 \text {, etc. }\end{array}$ & $\begin{array}{l}\text { Analgésico } \\
\text { Antitusigeno, } \\
\text { Antiasmático }\end{array}$ \\
\hline Amapola silvestre & Papaver thoeas & $\begin{array}{l}\text { Papaver album } 3,18,2 / \\
4,17,1 / 4,21,2 / 5,24,4 / \\
\text { etc. }\end{array}$ & $\begin{array}{l}\text { Papaver silvaticus } 22, \\
73,220\end{array}$ & $\begin{array}{l}\text { Analgésico } \\
\text { Sedante, Diurético }\end{array}$ \\
\hline Ameos & Ammi majus & - & Ameus-Ami 121 & En el Cólico \\
\hline Amomo & $\begin{array}{l}\text { Amomum } \\
\text { cardamomum }\end{array}$ & $\begin{array}{l}\text { Amomo } 3,18,12 / 5,18,3 / \\
5,18,7 \mathrm{~B} / 5,18,8 / 6,7,3 \mathrm{~A}\end{array}$ & $\begin{array}{l}\text { Amomo } 70,126,177, \\
271\end{array}$ & $\begin{array}{l}\text { Analgésico, } \\
\text { Emoliente, Antidoto }\end{array}$ \\
\hline Amoniacal & $\begin{array}{l}\text { Dorema ammoniacum } \\
\text { (perfume) }\end{array}$ & $\begin{array}{l}\text { Thyamiama } 5,18,7 \mathrm{~B} / \\
5,18,9 / 5,18,10 / 5,18 \\
14 / 5,18,24 / 5,18,34 /\end{array}$ & Thymiama 258 & $\begin{array}{l}\text { Analgésico, Erosivo, } \\
\text { Emoliente, } \\
\text { Madurativo }\end{array}$ \\
\hline Amoniaca! (Goma) & $\begin{array}{l}\text { Dorema ammoniacum } \\
\text { (goma) }\end{array}$ & $\begin{array}{l}\text { Ammoniacum, 5,5,2/ } \\
5,11 / 5,15 / 5,18,2 / 5,18 \\
2 / 5,18,5 / 5,18,6 / \text { etc. }\end{array}$ & $\begin{array}{l}\text { Ammoniacum 28,35,79, } \\
82,128,177,201,202, \\
206,209,213, \text { elc. }\end{array}$ & $\begin{array}{l}\text { Analgésico, } \\
\text { Emoliente, } \\
\text { Antiinflamatorio, }\end{array}$ \\
\hline Amurca & Ver Alpechin & & & \\
\hline $\begin{array}{l}\text { Andropogon o } \\
\text { H. Barbuda }\end{array}$ & $\begin{array}{l}\text { Andropogon } \\
\text { ischaemum }\end{array}$ & - & $\begin{array}{l}\text { Schoenus } 70,120,125, \\
144,170,173,176,177, \\
269,271\end{array}$ & $\begin{array}{l}\text { Analgésico, } \\
\text { Antiinflamatorio } \\
\text { Antidoto }\end{array}$ \\
\hline Aneto o Eneldo & $\begin{array}{l}\text { Anethum } \\
\text { graveolens }\end{array}$ & $\begin{array}{l}\text { Anethum } 3,10.2 / 4,27 \text {, } \\
1 \mathrm{C} /\end{array}$ & Anethum 92, 109 & Analgésico \\
\hline Anis & $\begin{array}{l}\text { Pimpinella } \\
\text { anisum }\end{array}$ & $\begin{array}{l}\text { Anesum } 3,24,2 / 4,21,2 / \\
5,23,1 B / 5,23,3 / 5,25,5 / \\
5,25,12\end{array}$ & $\begin{array}{l}\text { Anisum } 52,70,113 \\
120,126,134,144,145, \\
152,170,173,177,260\end{array}$ & $\begin{array}{l}\text { Analgésico } \\
\text { Antidoto } \\
\text { En ej colsco }\end{array}$ \\
\hline
\end{tabular}


FÁRMACOS ORIGEN VEGETAL (Continuación)

\begin{tabular}{|c|c|c|c|c|}
\hline Español & Cientifico & En Celso & En Escribonio & Indicaciones \\
\hline Apio & \begin{tabular}{|l} 
Apium \\
graveolens
\end{tabular} & $\begin{array}{l}\text { Apium } 4,16,3 / 4,27,1 \mathrm{D} / \\
5,6,2 / 5,25,2 /\end{array}$ & $\begin{array}{l}\text { Apium } 52,70,92,120, \\
133,135,144,152, \\
173,183\end{array}$ & $\begin{array}{l}\text { Analégisco } \\
\text { Antitusigeno, } \\
\text { Antidoto, Erosivo, }\end{array}$ \\
\hline Apio caballuno & Smymium olosatrum & - & $\begin{array}{l}\text { Smymium (semilla) } \\
\text { Olosatrum 126, 158, } \\
195\end{array}$ & $\begin{array}{l}\text { Analgésico, } \\
\text { Antidoto (Pharico). } \\
\text { Enf. hepáticas }\end{array}$ \\
\hline Aristoloquia & Aristolochia clematitis & \begin{tabular}{|l|} 
Aristolochia $5,18,7 \mathrm{~B} /$ \\
$5,18,24 / 5,18,35 / 5,19,7 /$ \\
$5,19,18 / 5,19,13 / \mathrm{etc}$. \\
\end{tabular} & $\begin{array}{l}\text { Aristolochia, Malum } \\
\text { terrae } 63,70,165,166 \\
102,206,220,236\end{array}$ & $\begin{array}{l}\text { Emoliente, } \\
\text { Madurativo, } \\
\text { Antiinflamatorio, }\end{array}$ \\
\hline Arroz & Oryza sativa & Oriza $2,24,1 / 3,22,11$ & - & En Fiebres, Digestivo \\
\hline Artemisia & Artemisia vulgaris & - & Artemisia 106 & En el Cólico \\
\hline Arveja & Ervuum ervilia & $\begin{array}{l}\text { Ervum 5,5,2/5,15/5, } \\
16 / 5,27,13 \mathrm{~B} / 6,5,31 / 6 \\
15,2 /\end{array}$ & Ervum 165 & $\begin{array}{l}\text { Antidoto, Emoliente, } \\
\text { Detersivo, Limpia la } \\
\text { piel }\end{array}$ \\
\hline Asafétida o Lasei & Ferula silphium, & $\begin{array}{l}\text { Laser o Laserpitium, } \\
\text { Asatoetida } 3,16,2 / 4,6 \\
3 / 4,10,3 / 4,19,4 / 5,27,8\end{array}$ & $\begin{array}{l}\text { Laser 67, 70, 165, 174, } \\
175,177,192,196,197 \\
199\end{array}$ & $\begin{array}{l}\text { Antidoto, } \\
\text { Antiinflamtorio, En } \\
\text { enf. Gástricas }\end{array}$ \\
\hline Asaro & $\begin{array}{l}\text { Asarum } \\
\text { Europaeum }\end{array}$ & - & $\begin{array}{l}\text { Asarum 109, 110, 176, } \\
177\end{array}$ & $\begin{array}{l}\text { Antidoto, } \\
\text { En enlermedades } \\
\text { Gástricas }\end{array}$ \\
\hline Astódelo & Asphodelus ramosus & - & $\begin{array}{l}\text { Asfodelo, Astula regia } \\
254\end{array}$ & En Sarna \\
\hline Aspalato y Retama & $\begin{array}{l}\text { Calcycotoma } \\
\text { villosa o Genista } \\
\text { cinerea }\end{array}$ & $\begin{array}{l}\text { Aspalathus, Spartes } \\
5,24,1 / 6,9,5 /\end{array}$ & Aspalathus 110,269 & Analgésico \\
\hline Avellana & Corylus avellana & Abeliana $3,27,4 \mathrm{Bl}$ & $\begin{array}{l}\text { Nux avellana } 110,120 . \\
121\end{array}$ & $\begin{array}{l}\text { En Cólico y } \\
\text { enfermedades } \\
\text { gástricas }\end{array}$ \\
\hline Azatràn & Croccus sativus & \begin{tabular}{|l|} 
Crocus, Croci magmatis \\
$3,18,12 / 3,21,7 /$ etc. \\
Crocomagma: $6,6,25 \mathrm{~B} /$
\end{tabular} & $\begin{array}{l}\text { Crocus, 4, 5, 21, 22, 26, } \\
27,29 \text { etc. } \\
\text { Crocomagma: } 70\end{array}$ & $\begin{array}{l}\text { Analgésico, } \\
\text { Antiinflamatorio, } \\
\text { Emoliente }\end{array}$ \\
\hline Azucena & Lilium candidum & $\begin{array}{l}\text { Lilium } 5,11 / 5,18,6 \mathrm{~A} \\
5,27,12 \mathrm{C}\end{array}$ & - & Antidoto, Emoliente \\
\hline Balaustio & $\begin{array}{l}\text { Flor del granado usada } \\
\text { para curtir }\end{array}$ & - & Balaustium 85, 112 & $\begin{array}{l}\text { Hemostático, En } \\
\text { enfermedades graves }\end{array}$ \\
\hline Bálsamo & Resina del mismo & \begin{tabular}{|l|} 
Balsamum $3,21,7 / 5,3 /$ \\
$5,4 / 5,5 / 5,6 / 5,18,3 / 5,20$ \\
$6 / 5,23,1 \mathrm{~B} /$ \\
\end{tabular} & $\begin{array}{l}\text { Opobalsamum } 33,38, \\
126,170,176,177\end{array}$ & $\begin{array}{l}\text { Emoliente, Erosivo, } \\
\text { Detersivo, Antidoto, } \\
\text { Madurativo } \\
\end{array}$ \\
\hline Báłsado (madera de) & $\begin{array}{l}\text { Batsamodendron } \\
\text { gilaedensis }\end{array}$ & $\begin{array}{l}\text { Xylobalsamum } 5,18, \\
7 \mathrm{~B} / 5,24,1 /\end{array}$ & Xylobalsamum 110,269 & $\begin{array}{l}\text { Analgésico, } \\
\text { Emoliente, } \\
\text { Espasmolitico }\end{array}$ \\
\hline $\begin{array}{l}\text { Bedelio o Palma } \\
\text { vinifera }\end{array}$ & \begin{tabular}{|l} 
Borasus \\
flabeliformis
\end{tabular} & $\begin{array}{l}\text { Bdella o Bdellium } 5,4 / \\
5,5,2 / 5,12 / 5,15 / 5,18 \\
5 / 5,18,6 / 5,18,7 \text { B/etc. }\end{array}$ & Bdelium 138 & $\begin{array}{l}\text { Epispástico, } \\
\text { Emoliente, Erosivo, } \\
\text { Detersivo, }\end{array}$ \\
\hline Beleño blanco & Hyosciamus albus & - & $\begin{array}{l}\text { Altercum albus } 90,173, \\
220\end{array}$ & $\begin{array}{l}\text { Antitusigeno, } \\
\text { Antidiarreico, } \\
\text { Emoliente }\end{array}$ \\
\hline
\end{tabular}


FÁRMACOS ORIGEN VEGETAL (Continuación)

\begin{tabular}{|c|c|c|c|c|}
\hline Español & Cientifico & En Celso & En Escribonio & Indicaciones \\
\hline $\begin{array}{l}\text { Beleño negro o } \\
\text { Hirba de Apolo }\end{array}$ & Hyosciamus niger & $\begin{array}{l}\text { Hyosciamus } 3,18,12 / \\
3,27,2 \mathrm{C} / 5,18,29 / 5,25 \\
2 / 5,27,12 \mathrm{~B} /\end{array}$ & $\begin{array}{l}\text { Hyosciamus, Altercum } \\
52,54,89,90,91,82,93 \\
95,108,112,121,147\end{array}$ & $\begin{array}{l}\text { Antirreumático, } \\
\text { Analgésico, } \\
\text { Espasmolitico }\end{array}$ \\
\hline Bellota unguentaria & Moringa pterygosperma & $\begin{array}{l}\text { Myrobalanus o Balanus } \\
\text { Myrepsica } 4,16,4 / 5,18 \\
4 / 6,2,2 / 6,5,3 / 6,7,3 \mathrm{~A}\end{array}$ & $\begin{array}{l}\text { Myrobalanus o Balanus } \\
129,131,261\end{array}$ & $\begin{array}{l}\text { Analgésico, } \\
\text { En Enfermedades del } \\
\text { bazo }\end{array}$ \\
\hline Berro & Nasturtium officinale & $\begin{array}{l}\text { Nasturtium } 4,8,3 / 4,16,3 / \\
4,24,2 / 5,2 /\end{array}$ & $\begin{array}{l}\text { Nasturtium } 95,96,129 \\
131\end{array}$ & $\begin{array}{l}\text { Diurético, } \\
\text { Cicatrizante, } \\
\text { En ent del bazo }\end{array}$ \\
\hline Bolsa de Pastor & Capsiella bursapastoris & Thlaspis $5,23,3 \mathrm{~B}$ / & Thlaspis 170 & Antidoto \\
\hline Buprestis o Perfoliada & Bupleurum rotundifolium & - & Buprestis 190 & Veneno \\
\hline Calabaza & Cuburbitas diferentes & Cucurbita $2,20,1 / 2,18$ I & Cucurbita 39 & Analgésico en oidos \\
\hline $\begin{array}{l}\text { Camedrio (encina } \\
\text { (enana). } \\
\text { Germandrina }\end{array}$ & Teucrium chamaedris & - & Camaedrium 106 & $\begin{array}{l}\text { Antiespasmodico } \\
\text { intestinal }\end{array}$ \\
\hline Camedrio Acuático & Teucrium scordium & - & Scordium 177 & Antidoto \\
\hline Canela & $\begin{array}{l}\text { Cinnamomum } \\
\text { Zeylanicum }\end{array}$ & $\begin{array}{l}\text { Cinnamomum } 3,21,7 / \\
4,27,1 E / 5,6,2 / 5,11 / 5 \\
18,3 / 5,18,33 / \text { etc. }\end{array}$ & $\begin{array}{l}\text { Cinnamomum } 70,93,106 \\
110,121,125,126,144, \\
145,152,166,173,176\end{array}$ & $\begin{array}{l}\text { Erosivo, } \\
\text { Analgésico, } \\
\text { Antiintiamatorio }\end{array}$ \\
\hline Caña Común & Arundo donax & $\begin{array}{l}\text { Arundo o Harundo } \\
5,26,35 / 6,7,10 \text { I }\end{array}$ & - & $\begin{array}{l}\text { Epispástico, } \\
\text { Analgésico (otitis) }\end{array}$ \\
\hline Cañaheja & Ferula communis & Faerula $4,17,11$ & - & Diurético \\
\hline Cardamomo & Eletteria cardamomum & $\begin{array}{l}\text { Cardamomum } 3,21,7 / 5, \\
2 / 5,6 / 5,15 / 5,18,3 / 5,18,7 \\
\mathrm{~B} / 5,18,8 / 5,18,14 \mathrm{~B} / \mathrm{etc}\end{array}$ & $\begin{array}{l}\text { Cardamum } 170,258, \\
261,265,269,271\end{array}$ & $\begin{array}{l}\text { Cicatrizante } \\
\text { Antidoto, } \\
\text { Erosivo, }\end{array}$ \\
\hline $\begin{array}{l}\text { Cardo ajonjero, } \\
\text { Ajonjera o Camaleón }\end{array}$ & Atractylis gummitera & Chamaleon $5,18,331$ & Ixia, Chamaleon 192 & $\begin{array}{l}\text { Tóxico, Antigotoso, } \\
\text { Antirreumático }\end{array}$ \\
\hline Cardo corredor & Eryngium campestris & - & Enngium 153, 165 & $\begin{array}{l}\text { Antidoto mord. serp. } \\
\text { Antirreumático }\end{array}$ \\
\hline Cártamo o Alazor & Carthamus tinctorius & - & Cnecus 135 & Laxante \\
\hline Casia & Cassia angustifolia & $\begin{array}{l}\text { Casia o Cassia } 3,21,7 / \\
5,2,15,6 / 5,15 / 5,18,3 / 5 \\
18,7 \mathrm{~B} / 5,18,14 \mathrm{~B} / \mathrm{etc} \\
\end{array}$ & $\begin{array}{l}\text { Casia } 36,70,93,125 \\
126,144,173,176,177 \\
269,271\end{array}$ & $\begin{array}{l}\text { Antinflamatorio, } \\
\text { Analgésico, } \\
\text { Antirreumático, }\end{array}$ \\
\hline Cebada & Hordeum vulgare & $\begin{array}{l}\text { Hordeus } 3,27,2 \mathrm{C} / 5,18 \\
4 / 5,27,8 / 5,28,19 \mathrm{D} / 6,5 \\
3 / 6,6,1 \text { L/6,6,39 C/8,9,1 }\end{array}$ & $\begin{array}{l}\text { Hordeus } 59,105,159 \\
160,179,184,189,225 \\
252\end{array}$ & $\begin{array}{l}\text { Antidoto mord. serp. } \\
\text { Analgésico, } \\
\text { En ent. del bazo, }\end{array}$ \\
\hline Cebolla & Allium cepa & Cepa $3,20,1 / 4,4 / 5,2 /$ & Cepa 174, 263 & $\begin{array}{l}\text { Cicatrizante, } \\
\text { Contra la sarna }\end{array}$ \\
\hline Cedro u Oxicedro & Juniperus oxycedrus & $\begin{array}{l}\text { Cedrus, Cedria (resina) } \\
5,11 \text {, }\end{array}$ & $\begin{array}{l}\text { Cedrus, Cedria (resina) } \\
59,186,232\end{array}$ & $\begin{array}{l}\text { Analgésico, } \\
\text { Antiinfllamatorio }\end{array}$ \\
\hline Celiconia Menor & Ficaria ranunculoides & - & Bathrachium 174 & Cicatrizante \\
\hline Centáurea & Centaurea salonitana & $\begin{array}{l}\text { Centaurius } 5,27,10 / 6 \\
7,2 /\end{array}$ & $\begin{array}{l}\text { Centaurius, Fel terrae } \\
227\end{array}$ & $\begin{array}{l}\text { Antinflamtorio, } \\
\text { Antihemorroidal, } \\
\text { Antidoto mord. serp. }\end{array}$ \\
\hline Centeno & Lolium temulentum & $\begin{array}{l}\text { Lolium } 5,23,3 / 5,22,2 \mathrm{Cl} \\
5,27,9 / 5,12 / 8,9,1 \mathrm{E} /\end{array}$ & - & $\begin{array}{l}\text { Autidoto, } \\
\text { Corrosivo, Fpispastico, }\end{array}$ \\
\hline
\end{tabular}


FÁRMACOS ORIGEN VEGETAL (Continuación)

\begin{tabular}{|c|c|c|c|c|}
\hline Español & Cientitico & En Celso & En Escribonio & Indicaciones \\
\hline $\begin{array}{l}\text { Centidonia, } \\
\text { Celidonia o Sanguinaria } \\
\text { Mayor }\end{array}$ & Polygonum aviculare & $\begin{array}{l}\text { Chelidonium o Herba } \\
\text { hirundinis, Polygonum } \\
3,22,13 / 4,15,3 / 5,1 / \\
\end{array}$ & $\begin{array}{l}\text { Chelidonium 2, 46, } 83, \\
174,193\end{array}$ & $\begin{array}{l}\text { Antihemorrágico, } \\
\text { Vulnerario, } \\
\text { Antidoto }\end{array}$ \\
\hline Centunculo & Polygonum convolvulus & - & Centunculus 121 & En el cólico \\
\hline Ciclamen & Ciclamen Europaeum & - & Cyclamimum $6,8,71$ & Antiinflamatorio \\
\hline Cicuta & Conium maculatum & $\begin{array}{l}\text { Cicuta } 5,6,2 / 5,7 / 5,15 / \\
5,18,1 / 5,25,5 / 6.6,1 / / \\
6,17,1 /\end{array}$ & Conium 179 & $\begin{array}{l}\text { Tónico general, } \\
\text { Refrescante, } \\
\text { Erosivo, Emoliente }\end{array}$ \\
\hline Cidra & $\begin{array}{l}\text { Citrus medica o } \\
\text { Malus medica }\end{array}$ & - & Citreus 158 & Antirreumático \\
\hline Cincoenrama & Potentilla reptans & $\begin{array}{l}\text { Quinquefolium 4,22,2/ } \\
6,9,2 / 2,33 /\end{array}$ & Quinquefolius 53 & Analgésico dental \\
\hline Cinoglosa & Cynoglossum officinale & Canina lingua $5,27,13 \mathrm{~N}$ & - & En quemaduras \\
\hline Ciprés & $\begin{array}{l}\text { Cupressus } \\
\text { sempervirens }\end{array}$ & $\begin{array}{l}\text { Cupressus } 3,21,7 / 4,16, \\
4 / 5,11 / 6,6,16 \mathrm{~B} / 7,27,21\end{array}$ & Cupressus 53,233 & $\begin{array}{l}\text { Diurètico, } \\
\text { Antiinflamatorio, } \\
\text { Antinflam. ocular, }\end{array}$ \\
\hline Ciruelo & Cordia mixa & - & Myxum 141 & Vermifugo \\
\hline Citiso (Retama) & Cytisus scoparius & $\begin{array}{l}\text { Cytisus, Spartes } 4 \text {. } \\
16,3 / 6,9,4 / 6,9,5 /\end{array}$ & - & $\begin{array}{l}\text { Diurético, } \\
\text { Analgésico dental, } \\
\text { En ent. del bazo }\end{array}$ \\
\hline Clematide & Ver Vid alba & & & \\
\hline Col o Berza & Brassica oleracea & Brassica 4,24,2/ & Brassica 121, 160 & $\begin{array}{l}\text { Antirreumático, } \\
\text { Vermifugo }\end{array}$ \\
\hline Cólchico o Cólquico & Colchicum autumnale & - & Ephemeron 193 & Tóxico \\
\hline Coloquintida & Cuccumis colocynthis & Cucurbitae silvestris & $\begin{array}{l}\text { Cucurbitae silvestris } \\
\text { Coloquintida 99, 106, } \\
107,154,155\end{array}$ & $\begin{array}{l}\text { Antirreumático, } \\
\text { Antiespasmódico } \\
\text { intestinal }\end{array}$ \\
\hline Comino & Cumminum cyminum & $\begin{array}{l}\text { Cumminum, Silus } 4, \\
15,3 / 5,18,15 / 5,28,19 \mathrm{C} / \\
6,18,6 \mathrm{~A} 6,19,6 \mathrm{~B} / 8,9,1 \\
\end{array}$ & $\begin{array}{l}\text { Cumminum, Silus } 119 \text {, } \\
134,165,233\end{array}$ & $\begin{array}{l}\text { Antiintlamatorio, } \\
\text { Emoliente, } \\
\text { Antiespasmódico }\end{array}$ \\
\hline Conila & Ver Ajedrea & & & \\
\hline Consuela mayor o Sinfito & Simphythum officinale & - & Symphytum 83,86 & Antihemorrágico \\
\hline Coriandro & Coriandrum sativum & $\begin{array}{l}\text { Coriandrum } 2,27 / 6,18 \text {, } \\
1 / 5,28,15 \mathrm{EI}\end{array}$ & Coriandrum 185, 244 & $\begin{array}{l}\text { Tóxico general, } \\
\text { Emoliente, Diuretico, }\end{array}$ \\
\hline Coscoja & Quercus coccifera & $\begin{array}{l}\text { Coccum Cnidium } 5,5 \\
2 / 5,8,1 / 5,18,7 \mathrm{~B} /\end{array}$ & Coccum 134, 135 & $\begin{array}{l}\text { Diurético, Cáustico, } \\
\text { Detersivo }\end{array}$ \\
\hline $\begin{array}{l}\text { Costo o Hierba de } \\
\text { Santa Maria }\end{array}$ & Saussurea lapsa & $\begin{array}{l}\text { Costus } 3,27,1 / 4,21,2 / 4, \\
27,10 / 5,5,2 / 5,18,3 / 5 \\
20,6 / 5,23,1 \mathrm{~B} / \mathrm{etc}\end{array}$ & $\begin{array}{l}\text { Costus } 70,121,125, \\
126,129,144,173,177, \\
269 \\
\end{array}$ & $\begin{array}{l}\text { Antidoto, } \\
\text { Emoliente, } \\
\text { Diurético, }\end{array}$ \\
\hline Cyperus & Ver Junco articulado & & & \\
\hline Cyperus cuadrado & Cyperus longus & $\begin{array}{l}\text { luncus cuadratus } 3,21 \text {, } \\
7 / 5,4 / 5,11 / 5,18,8 / 5,24 \\
1 / 6,11,2 / \text { etc. }\end{array}$ & - & $\begin{array}{l}\text { Diurético, } \\
\text { Emoliente, } \\
\text { Detersivo }\end{array}$ \\
\hline Cyperus redondo & $\begin{array}{l}\text { Cyperus rotundus o } \\
\text { Sculentus }\end{array}$ & $\begin{array}{l}\text { luncus rotundus } 3,21,7 / \\
4,21,2 / 5,18,3 / 5,23,1 \mathrm{~B} / \\
5,23,2 / 5,23,3 \mathrm{~B} 6 \mathrm{elc} \text {. }\end{array}$ & $\begin{array}{l}\text { Iuncus, Gladiolo (raiz } \\
\text { del junco) } 82\end{array}$ & $\begin{array}{l}\text { Diurético, } \\
\text { Antidoto }\end{array}$ \\
\hline
\end{tabular}


FÁRMACOS ORIGEN VEGETAL (Continuación)

\begin{tabular}{|c|c|c|c|c|}
\hline Español & Científico & En Celso & En Escribonio & Indicaciones \\
\hline Chamaepitis o Pinillo & Ajuga chamaepitys & Chamaepitys 5,41 & Chamaepitys 187,188 & Ulcerativo, Antidoto \\
\hline Chirivia & Ver Pastinaca & & & \\
\hline Dátil (Palmera datilera) & Phoenix datilifera & $\begin{array}{l}\text { Palmulaeve, cariola } 4 \text {, } \\
9,3 / 4,26,8 / 5,22,9 / 6,6, \\
5 \mathrm{~B} /\end{array}$ & Cariota $74,109,148$ & $\begin{array}{l}\text { Emoliente, } \\
\text { Cicatrizante, } \\
\text { Antiespasmódico }\end{array}$ \\
\hline Dictamo de Creta & Origanum dictammum & $\begin{array}{l}\text { Dictamnus Creticus } \\
5,25,13 /\end{array}$ & Dicatmnus 106,177 & $\begin{array}{l}\text { Espasmolítico, } \\
\text { Facilita expulsión del } \\
\text { feto muerto }\end{array}$ \\
\hline Doricno & $\begin{array}{l}\text { Dorycnium } \\
\text { suffructicosum }\end{array}$ & - & Dorycnium 191 & Tóxico \\
\hline Dukamara & Ver Solano & & & \\
\hline Ebano & Dyospirus ebenum & $\begin{array}{l}\text { Ebenus, Hebenus } 3,21 \\
7 / 5,7 / 5,12 / 5,13\end{array}$ & - & $\begin{array}{l}\text { Analgesico, } \\
\text { Epispástico, } \\
\text { Corrosivo }\end{array}$ \\
\hline $\begin{array}{l}\text { Elaterio (pepino } \\
\text { silvestre) }\end{array}$ & Ecbalium elaterium & $\begin{array}{l}\text { Elaterium, Cocomerus } \\
\text { agrestis } 4,31,6 / 5,12 / 5, \\
18,7 \mathrm{~B} 75,21,1 / \text { etc. }\end{array}$ & $\begin{array}{l}\text { Elaterium o Cucumis } \\
\text { (jugo) } 70,80,156,224 \text {, } \\
237\end{array}$ & $\begin{array}{l}\text { Epispastico, } \\
\text { Erosivo, } \\
\text { Antirreumático, }\end{array}$ \\
\hline Eleboro blanco & Veratrus album & $\begin{array}{l}\text { Veratrus aibum } 3,18 \\
20 / 3,23,3 / 3,23,5 / 2,25 \\
2 / 5,6,2 / 5,8 /\end{array}$ & Veratrus album 10 & $\begin{array}{l}\text { Emético, } \\
\text { Cáustico, } \\
\text { Estornutatorio }\end{array}$ \\
\hline Eléboro negro & Helleborus nigram & $\begin{array}{l}\text { Veratrus nigrum } 3,18, \\
20 / 3,23,3 / 3,23,5 / 3,25 \\
2 / 5,6,2 / 5,8\end{array}$ & Veratrus nigrum 10 & $\begin{array}{l}\text { Detersivo, } \\
\text { Erosivo, } \\
\text { Cáustico, }\end{array}$ \\
\hline Endivia & Cichorum endivia & Intubus $3,22,11 / 4,16,2 /$ & Intubus 104 & $\begin{array}{l}\text { Antiacido, En enf. de } \\
\text { bazo }\end{array}$ \\
\hline $\begin{array}{l}\text { Enebro (Resina o } \\
\text { Sandaraca) }\end{array}$ & Juniperus communis & - & Sandaraca 61 & $\begin{array}{l}\text { Antiinflamatorio } \\
\text { gingival }\end{array}$ \\
\hline $\begin{array}{l}\text { Erisimo o H. de los } \\
\text { Cantores o Jaramago }\end{array}$ & $\begin{array}{l}\text { Sysimbrium } \\
\text { officinale }\end{array}$ & $\begin{array}{l}\text { Erysimum } 5,18,25 ! \\
5,25,14 !\end{array}$ & - & $\begin{array}{l}\text { Emoliente, } \\
\text { En partos dificiles }\end{array}$ \\
\hline Eruca & Brassica eruca & $\begin{array}{l}\text { Eruca } 4,16,3 / 4,28,2 / 5 \\
8 !\end{array}$ & - & $\begin{array}{l}\text { Cáustico, Diurético, } \\
\text { Facilita produccion } \\
\text { semen }\end{array}$ \\
\hline $\begin{array}{l}\text { Escamonea } \\
\text { H. Cantábrica }\end{array}$ & $\begin{array}{l}\text { Convulvulus } \\
\text { scammonia }\end{array}$ & $\begin{array}{l}\text { Scammonia, Herba } \\
\text { Cantábrica } 3,20,6 / 3, \\
24,2 / 4,24,1 / 5,6,2 / 5 \\
27,10 /\end{array}$ & Scamonia 140,254 & $\begin{array}{l}\text { Emético, } \\
\text { Vermifugo, Erosivo, } \\
\text { Antidoto mord. serp. }\end{array}$ \\
\hline Escaravia & Sisum sisarum & Siser $2,21,1 / 2,33,21$ & - & Repercusivo \\
\hline $\begin{array}{l}\text { Escila o Cebolla } \\
\text { albarrana }\end{array}$ & Scilla urginea maritima & $\begin{array}{l}\text { Scilla } 3,21,10 / 3,27, \mathrm{D} / \\
4,10,3 / 5,18,27 / 5,28,12 \\
\mathrm{~K} 6,8,1 \mathrm{Cl}\end{array}$ & $\begin{array}{l}\text { Scilla o Lactuca marina } \\
75,79,126,129,134 \\
174,176\end{array}$ & $\begin{array}{l}\text { Antitusigeno, } \\
\text { Emoliente, } \\
\text { Antidisnéico, }\end{array}$ \\
\hline $\begin{array}{l}\text { Escolopendra o } \\
\text { Asplenio }\end{array}$ & Asplenium scolopendra & - & $\begin{array}{l}\text { Calcitraga o Scolopendra } \\
150,153\end{array}$ & $\begin{array}{l}\text { En Mal de piedra. } \\
\text { Entermedades bazo }\end{array}$ \\
\hline Espárrago & Asparagus officinale & Asparagus 4,16,2) & Asparagus 79 & $\begin{array}{l}\text { Antidisnéico, } \\
\text { Entermedades bazo }\end{array}$ \\
\hline Espelta & Triticum spelta & $\begin{array}{l}\text { Halica o Zea } 3,19,5 / \\
3,22,11 / 4,28,21\end{array}$ & $\begin{array}{l}\text { Halica o Zea } 70,104, \\
251\end{array}$ & $\begin{array}{l}\text { Digetivo, } \\
\text { Antinflamatorio, } \\
\text { Aumenta semen }\end{array}$ \\
\hline
\end{tabular}


FÁRMACOS ORIGEN VEGETAL (Continuación)

\begin{tabular}{|c|c|c|c|c|}
\hline Español & Cientifico & En Celso & En Escribonio & Indicaciones \\
\hline Espondilio & Heracleum sphondylium & - & Sphondylium 2 & Analgésico en cefaleas \\
\hline Estafisagria & $\begin{array}{l}\text { Delphynium } \\
\text { staphisagria }\end{array}$ & $\begin{array}{l}\text { Para Celso es igual } \\
\text { que Uvas } \\
\text { Taminias } 3,21,7\end{array}$ & $\begin{array}{l}\text { Pedicularia, Staphidis } \\
\text { agria } 8,166,227,243\end{array}$ & $\begin{array}{l}\text { Antidoto, } \\
\text { Vermifugo, } \\
\text { Analgésico cefaleas }\end{array}$ \\
\hline Estorax o Estoraque & Styrax officinale & $\begin{array}{l}\text { Styrax, Storax } 3,27,1 / \\
5,3 / 5,5 / 5,6,2 / 5,11 / 5 \\
15 / 5,18,5 / 5,18,22 / \text { etc. }\end{array}$ & $\begin{array}{l}\text { Styrax o Storax } 88,89, \\
179,262,269\end{array}$ & $\begin{array}{l}\text { Madurativo, } \\
\text { Detersivo, } \\
\text { Diaforético, Erosivo }\end{array}$ \\
\hline $\begin{array}{l}\text { Euforbia, Titimalo o } \\
\text { Ciparisio }\end{array}$ & Euphorbia paralias & $\begin{array}{l}\text { Lactuca marina, } \\
\text { Tithymalus } 3,21,13 / 5,7 / \\
5,18,14\end{array}$ & Eurphorbium 38,67 & $\begin{array}{l}\text { Antinflamatorio, } \\
\text { Emoliente, } \\
\text { Aclara la vista }\end{array}$ \\
\hline Fanogreco o Alholva & $\begin{array}{l}\text { Trigonella toenum. } \\
\text { graecum }\end{array}$ & $\begin{array}{l}\text { Foenum Graecum } 4,6, \\
5 / 5,18,12 / 5,12,2 / 5,21 \\
2 / 5,28,11 \mathrm{~F} / \text { etc. }\end{array}$ & $\begin{array}{l}\text { Faenum Graecum 118, } \\
260,268,269\end{array}$ & $\begin{array}{l}\text { Antiinflamatorio, } \\
\text { Emoliente, } \\
\text { Enf. utero }\end{array}$ \\
\hline Farro (semilla) & $\begin{array}{l}\text { Parecida a Triticcum } \\
\text { spelta }\end{array}$ & - & Farris 135 & $\begin{array}{l}\text { En sarna y otras } \\
\text { enfermedades dérmicas }\end{array}$ \\
\hline Goma Alejandrina & & & $\begin{array}{l}\text { Commis Alexandrina } 24, \\
73,74\end{array}$ & $\begin{array}{l}\text { Antidisnéico, } \\
\text { Antitusigeno }\end{array}$ \\
\hline Goma Pérsica & & & Sarcocolla 22 & $\begin{array}{l}\text { Antinflamatorio, } \\
\text { Anticatarrat }\end{array}$ \\
\hline Gálbano (Resina) & $\begin{array}{l}\text { Ferula galbanifera } 0 \\
\text { Bubon }\end{array}$ & $\begin{array}{l}\text { Galbanum } 3,20,1 / 3 \\
21,7 / 4,8,3 / 5,3 / 5,4 / 5,6 / \\
5,15 / 5,18,2 / 5,18,5 / \text { etc. }\end{array}$ & $\begin{array}{l}\text { Galbanum } 81,82,89 \\
116,129,170,173,195, \\
205,206,210,213,225\end{array}$ & $\begin{array}{l}\text { Diurético, } \\
\text { Madurativo, } \\
\text { Emoliente, Erosivo }\end{array}$ \\
\hline Genciana & Gentiana lutea & Gentiana $5,23,3 /$ & Gentiana $170,176,177$ & Antidoto \\
\hline Gladiolo & Ver Junco & & & \\
\hline Glaucio & Glaucium luteum & - & Glauceus 22 & Emoliente \\
\hline Gomas & & $\begin{array}{l}\text { Gummis, Gummis } 5,1 / \\
5,2 / 5,18,1 / 6,6,3 / 5,20 \\
5 / 5,23,1 \mathrm{~B} / 5,23,3 / \\
\end{array}$ & $\begin{array}{l}\text { Commis, Cummis 111, } \\
142,176,177,186, \\
234,248 \\
\end{array}$ & $\begin{array}{l}\text { Antidoto } \\
\text { Emoliente, } \\
\text { Hemostático, }\end{array}$ \\
\hline Granada & $\begin{array}{l}\text { Punicus granatum, } \\
\text { Malicorium }\end{array}$ & $\begin{array}{l}\text { Punicum malum, } \\
\text { malicorum } 4,12,10 / 4 \text {, } \\
23,2 / 4,24,14,26,6 /\end{array}$ & $\begin{array}{l}\text { Granatus, Malum granati } \\
41,47,63,104\end{array}$ & $\begin{array}{l}\text { Antiinflamatorio, } \\
\text { Atractivo } \\
\text { Antidiarréico, }\end{array}$ \\
\hline Haba & Vicia faba & $\begin{array}{l}\text { Faba } 5,18,24 / 5,28,19 \\
\mathrm{C} / 5,28,21 /\end{array}$ & Faba 158,233 & $\begin{array}{l}\text { Antigotoso, } \\
\text { Antiinflamatorio, } \\
\text { Suavizante dérmico }\end{array}$ \\
\hline Haba Egipcia & Nelumbo nucitera & $\begin{array}{l}\text { Aegyptia faba } 6,7,1 \mathrm{E} \\
6,7,2 \mathrm{Cl}\end{array}$ & & $\begin{array}{l}\text { Antiinflamatorio en } \\
\text { oidos }\end{array}$ \\
\hline Halicacabo & Ver Alquequenje & & & \\
\hline $\begin{array}{l}\text { Heces de vino } \\
\text { (quemadas) }\end{array}$ & & \begin{tabular}{|l|} 
Faex (combusta) 3,12 \\
$9 / 5,8 / 5,18,23 / 5,22,2 \mathrm{Cl}$ \\
$5,28,11 \mathrm{~B} / 5,28,14 \mathrm{E} /$ \\
\end{tabular} & - & $\begin{array}{l}\text { Cáustico, } \\
\text { Corrosivo suave }\end{array}$ \\
\hline Helecho & Pteridium aquilinum & - & Filix $136,140,244$ & $\begin{array}{l}\text { Vermilugo, Detersivo } \\
\text { En Fuego Sagrado }\end{array}$ \\
\hline Heliotropo & Herba solaris & $\begin{array}{l}\text { Heliotropion. } \mathrm{H} \text {. Solaris } \\
2,27,5 \mathrm{~B}\end{array}$ & - & $\begin{array}{l}\text { Antidoto picadura } \\
\text { de escorpión }\end{array}$ \\
\hline Hibisco, Malvavisco & Althaea officinalis & $\begin{array}{l}\text { Hibiscus o lbiscus } 4,31 \\
4 !\end{array}$ & Hibiscus $80,82,160$ & $\begin{array}{l}\text { Antirreumatico, } \\
\text { Antigotoso, } \\
\text { Antiinflamatorio }\end{array}$ \\
\hline
\end{tabular}


FÁRMACOS ORIGEN VEGETAL (Continuación)

\begin{tabular}{|c|c|c|c|c|}
\hline Español & Cientifico & En Celso & En Escribonio & Indicaciones \\
\hline Hiedra & Hedera helix & $\begin{array}{l}\text { Hedera } 3,20,4 / 5,28 \\
4 \mathrm{E} / 6,9,6 / 8,10,7 \mathrm{~K}\end{array}$ & Hedrea $6,7,129$ & $\begin{array}{l}\text { Antinflamatorio, } \\
\text { Analgésico, } \\
\text { Ent. del bazo }\end{array}$ \\
\hline Hierba Betónica & Betonica officinalis & $\begin{array}{l}\text { Vettonica herba } 5,27 \text {, } \\
10 ?\end{array}$ & $\begin{array}{l}\text { Vettonica herba o H. } \\
\text { Sacra 141, 150, } 153\end{array}$ & $\begin{array}{l}\text { Antidoto mord. serp. } \\
\text { Vermifugo, } \\
\text { Mal de Piedra, }\end{array}$ \\
\hline Hierba de Apolo & Ver Beleño negro & & & \\
\hline Hierba Mercurial & Mercurialis annua & - & Mercurialis 135,148 & Antidoto, Diuretico \\
\hline Hierba Mora & Ver Solano & & & \\
\hline $\begin{array}{l}\text { Hierba Mural, } \\
\text { Parietaria o Partenion }\end{array}$ & Parietaria ofticinalis & $\begin{array}{l}\text { H. Muralis } 4,31,7 / 3 \\
18,9 / 2,33,2 / 5,28,18 \mathrm{~B} /\end{array}$ & $\begin{array}{l}\text { H. Urceolaris } 39,53,60 \text {, } \\
158\end{array}$ & $\begin{array}{l}\text { Antigotoso, } \\
\text { Analgésico dental, } \\
\text { Relrescante } \\
\end{array}$ \\
\hline Hierba Salivar & Ver Manzanilla & & & \\
\hline Higuera & Ficus carica & $\begin{array}{l}\text { Ficus } 3,21,14 / 4,7,3 / \\
4,10,1 / 4,14,2 / \mathrm{etc} \text {. }\end{array}$ & Ficus 190 & $\begin{array}{l}\text { Emoliente, } \\
\text { Epispástico, Detersivo }\end{array}$ \\
\hline $\begin{array}{l}\text { Higuera egipcia o } \\
\text { Sicomoro }\end{array}$ & Sycamorus Aegyptiaca & $\begin{array}{l}\text { F. Aegyptiaca o } \\
\text { Sycomorum } 3,18,13 / 5, \\
18,7 \mathrm{~B} /\end{array}$ & - & $\begin{array}{l}\text { Madurativo, } \\
\text { Sedante }\end{array}$ \\
\hline $\begin{array}{l}\text { Higuera silvestre } 0 \\
\text { Cabrahigo }\end{array}$ & Ficus carica silvestris & Caprificus 5,7/ & Capriticus 174,175 & $\begin{array}{l}\text { Antidisnéico, } \\
\text { Corrosivo }\end{array}$ \\
\hline $\begin{array}{l}\text { Higueruela o Trébol } \\
\text { hediondo }\end{array}$ & Psoralea bituminosa & - & \begin{tabular}{|l} 
Tritolium acutum 163, \\
165,177
\end{tabular} & Antidoto mord serp. \\
\hline Hinojo & Foeniculum officinale & $\begin{array}{l}\text { Feniculum 2,21/2,31/ } \\
2,33 \text {. }\end{array}$ & $\begin{array}{l}\text { Feniculum } 38,121,159, \\
160,176,177\end{array}$ & $\begin{array}{l}\text { Antidoto, Antigotoso } \\
\text { Antiespasmódico }\end{array}$ \\
\hline $\begin{array}{l}\text { Hiperico o H. de San } \\
\text { juán }\end{array}$ & Hypericum perioratum & $\begin{array}{l}\text { Hypericum } 5,20,6 / 5,23, \\
3 !\end{array}$ & & $\begin{array}{l}\text { Mal de la piedra, } \\
\text { Antidoto }\end{array}$ \\
\hline Hipocisto o Granadilla & Cytinus hypocistis & $\begin{array}{l}\text { Hypocistis } 5,7 / 5,23,1 \mathrm{~B} / \\
5,23,3 \mathrm{BI}\end{array}$ & $\begin{array}{l}\text { Hypocistis 85, 86, 112, } \\
113,142\end{array}$ & $\begin{array}{l}\text { Antidato, Hemostático, } \\
\text { Antidiarréico, }\end{array}$ \\
\hline Hisopo & Hissopus officinale & $\begin{array}{l}\text { Hysopum } 4,4 / 4,7,3 / 4,8 \\
3 / 4,12,2 / 4,13,5 / 4,14,2 / \\
4,15,3 / 4,16,3\end{array}$ & $\begin{array}{l}\text { Hyposum } 49,70,100, \\
262\end{array}$ & $\begin{array}{l}\text { Anitusigeno } \\
\text { Antidisnéico, } \\
\text { Diurético, } \\
\end{array}$ \\
\hline Hongos venenosos & & $\begin{array}{l}\text { Fungos inútiles } 5,27 \\
12 \mathrm{Cl}\end{array}$ & Fungis venenatis 198 & Tóxicos \\
\hline Incienso & $\begin{array}{l}\text { Boswelia carteri } \\
\text { (gomorresina del) }\end{array}$ & $\begin{array}{l}\text { Tus, Libanotus, } \\
\text { Olivanon, Masculus } 5 \text {, } \\
1 / 5,215,3 / 5,5 / 5,6 / 5,71 \\
5,8 / \text { etc. } \\
\end{array}$ & $\begin{array}{l}\text { Tus. Másculus 28, 30, } \\
31,32,56,74,86 \text {, etc. }\end{array}$ & $\begin{array}{l}\text { Hemostático } \\
\text { Vuinerario } \\
\text { Madurativo, }\end{array}$ \\
\hline Inula & Inula Helenium & Helenium 4,29,2/5,11/ & Inula 83, 128 & $\begin{array}{l}\text { Hemostático, } \\
\text { Antiinflamatorio, } \\
\text { Enf. del bazo } \\
\end{array}$ \\
\hline Jara & Cytus ladaniferus & $\begin{array}{l}\text { Ladanum } 3,21,7 / 5,12 / \\
5,19,18 / 5,26,32 / 6,1 / 6, \\
2,2 / \\
\end{array}$ & - & $\begin{array}{l}\text { Diuretico, } \\
\text { Crecepelo, } \\
\text { Epispástico, }\end{array}$ \\
\hline Jenijibre & Zingiber officinalis & Zingiber $5,23,3 \mathrm{~B}$ / & $\begin{array}{l}\text { luniperus } 109,126,165 \\
186,227\end{array}$ & $\begin{array}{l}\text { Antidoto, } \\
\text { Mordeduras ven. } \\
\text { Ent. higado y bazo }\end{array}$ \\
\hline
\end{tabular}


FÁRMACOS ORIGEN VEGETAL (Continuación)

\begin{tabular}{|c|c|c|c|c|}
\hline Español & Científico & En Celso & En Escribonio & Indicaciones \\
\hline Jiusquiamo & Ver Beleño negro & & & \\
\hline Junco articulado & Juncus articulatus & - & $\begin{array}{l}\text { Cyperus (raiz del Juncus } \\
\text { Articulatus) } 61,72,258, \\
265,269,271\end{array}$ & $\begin{array}{l}\text { Analgesico, } \\
\text { Emoliente, }\end{array}$ \\
\hline Lampazo o Bardana & Arctium major & $\begin{array}{l}\text { Personina planta } 2 \\
21 / 5,27,10 /\end{array}$ & Lapathum 57 & $\begin{array}{l}\text { Antidoto mord. serp. } \\
\text { Analgésico dental }\end{array}$ \\
\hline Laurel & Laurus nobilis & $\begin{array}{l}\text { Laurus } 3,20,4 / 4,2,7 / 4 \text {, } \\
15,3 / 5,12 / 5,19,12 / 5,19 \\
13 / 5,24,1 / 6,9,5 /\end{array}$ & Laurus 262, 263 & $\begin{array}{l}\text { Epispástico, } \\
\text { Analgésico, } \\
\text { Ent. hepáticas }\end{array}$ \\
\hline Laureola & Daphne laureola & & $\begin{array}{l}\text { Casia Daphnitidis 152, } \\
269\end{array}$ & $\begin{array}{l}\text { Analgésico, } \\
\text { En mal de la piedra }\end{array}$ \\
\hline Lavanda o Cantueso & Lavanduta stoechas & Stoechas $8,9,1 \mathrm{E}$ / & Stoechas $106,121,177$ & $\begin{array}{l}\text { Antitusigeno, Antidoto } \\
\text { Espasmolitico }\end{array}$ \\
\hline Lechuga & Lactuca sativa & Lactuca $3,22,11 / 4,16,2 /$ & Lactuca 104,138 & $\begin{array}{l}\text { Detersivo, } \\
\text { Enfermedades de } \\
\text { estómago y bazo }\end{array}$ \\
\hline Lechuga marina & Ver Euforbia o Titimalo & & & \\
\hline Lenteja & Lens sculenta & $\begin{array}{l}\text { Lens, Lenticulus } 4,9,3 / \\
4,26,8 / 5,5,2 / 5,7 / 5,10 / \\
6,18,2 / 6,13,1 / \text { etc. }\end{array}$ & Lens $114,130,230,234$ & $\begin{array}{l}\text { Detersivo, } \\
\text { Vuinerario, } \\
\text { Escarizante, }\end{array}$ \\
\hline Lentisco o Almáciga & Pistacia lentiscus & $\begin{array}{l}\text { Lentiscus, Mastic } 4,27 \\
1 \mathrm{E} / 4,31,7 / 5,6,2 / 5,18,22 / \\
5,18,24 / 6,7,2 \mathrm{~B} / 6,18,2 \mathrm{~F} / \\
\end{array}$ & $\begin{array}{l}\text { Lentiscus, Mastic } 60,61 \\
108,110\end{array}$ & $\begin{array}{l}\text { Erosivo, } \\
\text { Repercusivo, }\end{array}$ \\
\hline Licio & Rhamnus infectorius & $\begin{array}{l}\text { Lycium } 4,9,2 / 5,1 / 5,26 \\
30 \mathrm{c} / 5,28,16 \mathrm{C} / 6,6,5 \mathrm{~B} / \\
\text { etc. }\end{array}$ & Lycium $19,23,113,115$ & $\begin{array}{l}\text { Astrigente, } \\
\text { Hemostático, } \\
\text { Antidiarréico, }\end{array}$ \\
\hline Lino & Linum usitatissimo & $\begin{array}{l}\text { Linum } 4,16,4 / 5,2 / 5,11 / \\
5,12 / 5,28,11 \mathrm{~F} / 6,3,2 / 6 \\
18,6 \mathrm{~A} / 7,20,3 /\end{array}$ & Linum 96, 187, 189 & $\begin{array}{l}\text { Epispástico, } \\
\text { Vulneario, } \\
\text { Antidoto }\end{array}$ \\
\hline Lirio & Iris lilirica & \begin{tabular}{|l|} 
Iris $3,21,7 / 5,5 / 3,10,2 /$ \\
$5,15 / 5,16 / 5,18,3 / 5,18$ \\
$5 / 5,18,6 / 5,18,7 \mathrm{~B} /$ \\
\end{tabular} & $\begin{array}{l}\text { Iris Illirica o Iris } 44,79, \\
89,96,126,170,175,220 \\
225,236,255,258,260\end{array}$ & $\begin{array}{l}\text { Rubefaciente, } \\
\text { Antirreumático, } \\
\text { Analgésico, }\end{array}$ \\
\hline Lisimaquia & Lysimachia vulgaris & - & Lisimacon 46 & Hemostático \\
\hline Madreselva & Lonicera periclymenum & - & $\begin{array}{l}\text { Silvae matrem, } \\
\text { Periclimenon } 129\end{array}$ & $\begin{array}{l}\text { Enfermedades del } \\
\text { bazo }\end{array}$ \\
\hline Malobatro & Piper betel & $\begin{array}{l}\text { Malobathrum } 5,23,1 \mathrm{~B} \text { / } \\
5,23,3 \mathrm{~B}\end{array}$ & Malobathrum 120 & $\begin{array}{l}\text { Antidoto, Espasmolitico } \\
\text { (cólico) }\end{array}$ \\
\hline Malva & $\begin{array}{l}\text { Malva vulgaris } 0 \\
\text { rotundifolia }\end{array}$ & \begin{tabular}{|l|} 
Malva $4,10,4 / 5,27,12 \mathrm{~B} /$ \\
$5,28,11 \mathrm{~F} / 7,27,6 /$
\end{tabular} & Malva 99, 147, 184, 186 & $\begin{array}{l}\text { Emoliente, } \\
\text { Diurético, Antidoto }\end{array}$ \\
\hline Mandrágora & Mandragora officinalis & $\begin{array}{l}\text { Mandragora } 3,18,12 / 5 \text {, } \\
25,2 / 5,25,38 / 6,6,1 / 6 \text {, } \\
9,2 /\end{array}$ & Mandragora 106 & $\begin{array}{l}\text { Somnilero, } \\
\text { Analgesico dentai, } \\
\text { Espasmolitico }\end{array}$ \\
\hline $\begin{array}{l}\text { Manzanitla romana } \\
\text { u oficial }\end{array}$ & Anthemis nobilis & \begin{tabular}{|l|} 
Pyrethrum, $H$. Salivaris \\
$5,4 / 5,8 / 5,18,7 \mathrm{~B} / 5,18$ \\
$14 / 5,19,13 / 6,9,4 /$
\end{tabular} & $\begin{array}{l}\text { Pyrethrum } 9,55,69 \\
153,155,156\end{array}$ & $\begin{array}{l}\text { Delersivo, } \\
\text { Cáustico, Ent. colon, } \\
\text { bazo, etc. }\end{array}$ \\
\hline Manzano & Pyrus malus & $\begin{array}{l}\text { Malum (Amerina, } \\
\text { Scandiana) 4,26,6/6, } \\
13,4 /\end{array}$ & Malum 47, 104 & $\begin{array}{l}\text { Antiinílamatorio } \\
\text { (encias), } \\
\text { Hemostático }\end{array}$ \\
\hline
\end{tabular}


FÁRMACOS ORIGEN VEGETAL (Continuación)

\begin{tabular}{|c|c|c|c|c|}
\hline Español & Cientifico & En Celso & En Escribonio & Indicaciones \\
\hline Marrubio & Marrubium vulgare & $\begin{array}{l}\text { Marrubium } 3,22,14 / 3 \text {, } \\
27,4 \mathrm{C} / 4,9,2 / 5,7 / 5,16 / \\
5,22,2 / 5,27,13 \mathrm{~B} / \text { etc. }\end{array}$ & Marrubium 100, 106 & $\begin{array}{l}\text { Antitusigeno, } \\
\text { Vulnerario, En colitis, } \\
\text { Limpia la piel }\end{array}$ \\
\hline Mastic & Ver Lentisco & & & \\
\hline Mastuerzo & Lepidium sativum & - & Lepidium 174 & Emoliente \\
\hline Mejorana & Origanum maiorana & $\begin{array}{l}\text { Amaracus, } \\
\text { Sampsychus } 5,11 \text { I }\end{array}$ & Sampsuci $3,257,268$ & $\begin{array}{l}\text { Antiinflamatorio, } \\
\text { Analgésico }\end{array}$ \\
\hline Meliloto o Sértula & Melitotus officinalis & $\begin{array}{l}\text { Sertula Campana } 5,11 / \\
5,15 / 5,22,2 / 6,5,3 / 6,6,9 / \\
6,18,8 \mathrm{~A}\end{array}$ & $\begin{array}{l}\text { Sertula, Meliloto } 220 \\
258,269,271\end{array}$ & $\begin{array}{l}\text { Antiinflamtorio, } \\
\text { Emoliente. } \\
\text { Analgésico }\end{array}$ \\
\hline Melocotonero & Prunus persica & $\begin{array}{l}\text { Malum Persicum 6,7, } \\
10 /\end{array}$ & Nucieus Persicus 184 & $\begin{array}{l}\text { Antiinflamatorio, } \\
\text { Antidoto }\end{array}$ \\
\hline Membrillo & Cydonia vulgaris & $\begin{array}{l}\text { Malum Cotoneum 5,22, } \\
\mathrm{g} / 6,6,1 \mathrm{~L} / 6,18,8 \mathrm{~A}\end{array}$ & Cydoneus 104, 111,193 & $\begin{array}{l}\text { Antidiarréico, } \\
\text { Emoliente, } \\
\text { Antidoto, }\end{array}$ \\
\hline Membrillo, aceite de & Melinum & $\begin{array}{l}\text { Melinum 2,33,2/19,2/5, } \\
2 /\end{array}$ & - & Cicatrizante \\
\hline Menta Poleo & Mentha pulegium & $\begin{array}{l}\text { Pulegium } 4,18,3 / 4,27 \\
1 \mathrm{D} / 5,4 / 5,18,32 /\end{array}$ & Pulegium 3, 121 & $\begin{array}{l}\text { Estimulante, } \\
\text { Uicerativo } \\
\text { Analgésico (cefalea) }\end{array}$ \\
\hline Menta Silvestre & Mentha mentrastum & $\begin{array}{l}\text { Mentrastum 5,27,7/6, } \\
9,7 /\end{array}$ & Mentastrum 55 & $\begin{array}{l}\text { Analgésico dental, } \\
\text { Antidoto mord. serp. }\end{array}$ \\
\hline Menta Verde & Mentha viridis & $\begin{array}{l}\text { Mentha } 4,10,1 / 4,15,3 / \\
4,18,4 / 4,24,2 / 6,8,1 \mathrm{Cl} \\
6,11,5 /\end{array}$ & Mentha 2, 197, 244 & $\begin{array}{l}\text { Antitusigeno, } \\
\text { Vermifugo, } \\
\text { Diurético, }\end{array}$ \\
\hline Mirra & Balsamodendron myrtha & $\begin{array}{l}\text { Myrrh, Murra, Stacte } \\
3,16,2 / 3,21,6 / 3,21,7 / \\
4,21,2 / 5,2 / 5,3 / 5,6 / \text { etc }\end{array}$ & $\begin{array}{l}\text { Murra, Stace (Aceite de) } \\
5,23,26,27,36,37,52 \\
\text { etc. }\end{array}$ & $\begin{array}{l}\text { Estimulante, } \\
\text { Diuretico, } \\
\text { Antidoto, }\end{array}$ \\
\hline $\begin{array}{l}\text { Mirto espinoso o } \\
\text { Pie de Oca }\end{array}$ & $\begin{array}{l}\text { Chenopodium } \\
\text { scoparia }\end{array}$ & - & $\begin{array}{l}\text { Oxymirsine, Scopa regia } \\
153\end{array}$ & $\begin{array}{l}\text { Durético, } \\
\text { En Mal de la piedra }\end{array}$ \\
\hline Mirto o Arrayán & Myrtus communis & $\begin{array}{l}\text { Myrtus } 3,19,2 / 4,26,6 / \\
5,28,190 / 6,2,2 / 6,6,9 \mathrm{~B} / \\
6,6,16 \mathrm{~B} / 6,19,2 / \mathrm{etc}\end{array}$ & $\begin{array}{l}\text { Myrtus 49, 109, 115, 142 } \\
193,205,220\end{array}$ & $\begin{array}{l}\text { Repercusivo, } \\
\text { Refrescante, } \\
\text { Vulnerario }\end{array}$ \\
\hline Moral & Morus nigra & $\begin{array}{l}\text { Rubus, Morum 3,19,2/ } \\
4,7,3 / 4,23,2 / 4,24,1 / 4, \\
26,8 / 6,14,1 / \text { etc. }\end{array}$ & - & $\begin{array}{l}\text { Somnifero, } \\
\text { Detersivo, } \\
\text { Antiinflamatorio }\end{array}$ \\
\hline $\begin{array}{l}\text { Mostaza (negra y } \\
\text { blanca }\end{array}$ & Brassica (nigra y alba) & $\begin{array}{l}\text { Sinapis (nigra, alba) } \\
3,16,2 / 3,20,4 / 4,29 / 4, \\
3,3 / 4,6,6 / 4,19,3 / \\
\end{array}$ & $\begin{array}{l}\text { Sinapis (nigra, alba) } 9 \\
130,131,132,174,180\end{array}$ & $\begin{array}{l}\text { Erosivo, Atractivo, } \\
\text { Estimulante, } \\
\text { Calorifico, }\end{array}$ \\
\hline Muérdago & Viscum album & $\begin{array}{l}\text { Viscum } 5,18,6 / 5,18 \\
7 B / 5,18,15 / 5,18,23 / 5 \\
19,15 / 5,28,11 \mathrm{Cl}\end{array}$ & Viscum $82,214,229$ & $\begin{array}{l}\text { Analgésico, } \\
\text { Emoliente, } \\
\text { Atractivo }\end{array}$ \\
\hline Musgo & Musgos arbóreos & Muscus 2,32,21 & - & $\begin{array}{l}\text { Repercusivo, } \\
\text { Refrescante }\end{array}$ \\
\hline Nabo & Brassica napa & Rapa $5,28,6 \mathrm{~A}$ & Rapa 176, 177 & $\begin{array}{l}\text { Antiinflamatorio } \\
\text { Antidoto (rabia) }\end{array}$ \\
\hline Nabo silvestre & Brassica napa sculenta & - & Napi Selvatici 177 & Antidoto \\
\hline
\end{tabular}


FÁRMACOS ORIGEN VEGETAL (Continuación)

\begin{tabular}{|c|c|c|c|c|}
\hline Espan̄ol & Cientifico & En Celso & En Escribonio & Indicaciones \\
\hline Narciso & Narcissus serotinus & $\begin{array}{l}\text { Narcissus } 5,6,2 / 5 \\
11 / 5,15\end{array}$ & - & $\begin{array}{l}\text { Erosivo, } \\
\text { Antinflamtorio, } \\
\text { Emoliente }\end{array}$ \\
\hline Nardo Celtico & $\begin{array}{l}\text { Valeriana } \\
\text { Celtica }\end{array}$ & N. Galicum $5,23,3 \mathrm{~A}$ & $\begin{array}{l}\text { Saliunca, N. Galicum, } \\
\text { N. Célticum } 153,166 \text {, } \\
177,195,258,269\end{array}$ & $\begin{array}{l}\text { Antidoto, } \\
\text { Analgésico }\end{array}$ \\
\hline Nardo Cretense & Valeriana Italica & $\begin{array}{l}\text { Nardus } 3,21,7 / 4,21,2 / \\
5,3 / 5,11 / 5,18,3 / 5,18 \\
33 / 5,20,6 / 5,23,3 \mathrm{~B}\end{array}$ & Nardus $26,125,152$ & $\begin{array}{l}\text { Antidoto, } \\
\text { Diurético, } \\
\text { Enf. bazo e higado }\end{array}$ \\
\hline Nardo Indio & Valeriana Jatamansis & $\begin{array}{l}\text { N. spicae, } N \text {. Indicus, } \\
\text { N. Sirio } 4,27,1 E / 5,23, \\
2 / 6,6,6 / 6,6,9 / \text { etc. }\end{array}$ & $\begin{array}{l}\text { Nardi spicae, N. Indicus, } \\
\text { N. Sirio } 36,59,70,93, \\
106,110,113,120,121, \\
144 .\end{array}$ & $\begin{array}{l}\text { Antidoto, } \\
\text { Analgésico, } \\
\text { Emoliente (colirios) }\end{array}$ \\
\hline Neguilla o Ajenuz & Nigella sativa & $\begin{array}{l}\text { Git } 2,33 / 4,27 / 1 \mathrm{Cl} \\
5,28,18 \mathrm{~B} /\end{array}$ & Git $69,70,109,131,145$ & $\begin{array}{l}\text { Analgésico, } \\
\text { Emoliente, Diurético, }\end{array}$ \\
\hline Nepeta o H. Gatera & Nepeta cataria & $\begin{array}{l}\text { Nepeta } 4,4 / 4,7,3 / 4,15 \\
3 / 4,16,3 / 4,27,10 / 4,18 \\
32 / 4,27,8 / 6,9,2 / 6,13,1 /\end{array}$ & - & $\begin{array}{l}\text { Diurético, } \\
\text { Antidoto mord. serp. } \\
\text { Paralisis, }\end{array}$ \\
\hline Nerval & Nervalis arnoglossa & $\cdots$ & Nervalis, Polineiron 12 & En Epilepsia \\
\hline Nogal & Juglans regia & $\begin{array}{l}\text { Juglands, glands } 5.27 \text {, } \\
12 \mathrm{~B} /\end{array}$ & iuglands 143 & $\begin{array}{l}\text { Antidoto, } \\
\text { Entermedades riñón }\end{array}$ \\
\hline Nux Graeca & $\begin{array}{l}\text { Para Ceiso es la } \\
\text { almendra dulce }\end{array}$ & $\begin{array}{l}\text { Nux Graeca } 3,27,4 \mathrm{~B} / \\
4,31,7 / 5,6,2 / 5,11 / 5,15 / \\
5,22,2 / 5,28,15 \mathrm{E} / \mathrm{elc}\end{array}$ & - & $\begin{array}{l}\text { Vuinerario en vejiga } \\
\text { y rinones, } \\
\text { Antitusigeno }\end{array}$ \\
\hline Oenante & Jugo de la Vitis Alba & $\begin{array}{l}\text { Oenanthe } 3,21,7 / 5,5 / \\
5,8 / 5,28,3 \mathrm{D} /\end{array}$ & - & $\begin{array}{l}\text { Diurético, } \\
\text { Cáustico, Detersivo }\end{array}$ \\
\hline Olivo & Olea Europaea & $\begin{array}{l}\text { Olea } 5,7 / 5,22,2 / 5,28 \\
3 \mathrm{E} / 6,18,2 / 6,18,2 \mathrm{E} / 6,18, \\
2 \mathrm{~F} / 7,27,3\end{array}$ & $\begin{array}{l}\text { Olea } 104,114,142,205 \\
252\end{array}$ & $\begin{array}{l}\text { Corrosivo suave, } \\
\text { Espasmolitico } \\
\text { (disenteria) }\end{array}$ \\
\hline Olivo Enano u Olivilla & Cnecrum tricoccum & - & Chamalea $133,136,192$ & $\begin{array}{l}\text { Diurético, Detersivo, } \\
\text { Antidoto }\end{array}$ \\
\hline Ombligo de Venus & $\begin{array}{l}\text { Cotyledon umbilicus o } \\
\text { Saxifraga Cotyl. }\end{array}$ & - & Cotyledon 55 & Analgésico dental \\
\hline Omphacium & Jugo de uvas verdes & $\begin{array}{l}\text { Omphacium } 5,5,1 / 5,6 \\
2 / 5 / 5,28,16 \mathrm{~B} / 6,7,2 \mathrm{C} / \\
6,8,16 / 6,14,1 / \text { etc. }\end{array}$ & Omphacium $33,45,142$ & $\begin{array}{l}\text { Emoliente, } \\
\text { Erosivo, } \\
\text { Antiinflamatorio, }\end{array}$ \\
\hline Opio & Ver Amapola & & $\begin{array}{l}\text { Opium } 87,88,89,90,91 \\
92,93,95,112,115,120 \\
126,147,158,173\end{array}$ & $\begin{array}{l}\text { Antitusigeno, } \\
\text { Antiasmático, } \\
\text { Analgésico, }\end{array}$ \\
\hline Orégano & Origanum vulgare & $\begin{array}{l}\text { Tragoriganum } 5,11 / \\
3,21,7 /\end{array}$ & Tragoriganum 187, 192 & $\begin{array}{l}\text { Antidoto, } \\
\text { Antiinflamatorio }\end{array}$ \\
\hline Oreja de Raton & Ver Alsine & & & \\
\hline Ortiga mayor & $\begin{array}{l}\text { Urtica dioica } \\
4,24,2 / 5,18,14 /\end{array}$ & Urtica $3,27,2 \mathrm{C} / 4,10,4$ & Urtica 96, 99.184 & $\begin{array}{l}\text { Detersivo, Vermifugo, } \\
\text { Antidoto, }\end{array}$ \\
\hline Palma de coco & Coccos nucifera & - & Spatha 269 & $\begin{array}{l}\text { Analgésico en dolores } \\
\text { neurálgicos }\end{array}$ \\
\hline
\end{tabular}


FÁRMACOS ORIGEN VEGETAL (Continuación)

\begin{tabular}{|c|c|c|c|c|}
\hline Español & Cientifico & En Celso & En Escribonio & Indicaciones \\
\hline Panace (Asclepios) & Ferula nodosa & $\begin{array}{l}\text { Panáx } 5,25,38 / 5,25,11 / \\
5,27,7 / 5,27,8 / 5,27,12 / \\
\text { etc. }\end{array}$ & $\begin{array}{l}\text { Panax } 5,126,165,236 \\
260\end{array}$ & $\begin{array}{l}\text { Ulcerativo, } \\
\text { Analgesico, } \\
\text { Antidoto mord. serp. }\end{array}$ \\
\hline Panace (Opoponaco) & Opoponax Cheironium. & $\begin{array}{l}\text { Opoponax } 3,21,7 / 5,18, \\
5 / 5,23,1 \mathrm{~B} / 5,23,3 \mathrm{~B} / 6 . \\
6,25 \mathrm{~A} / 6,7,1 \mathrm{~F} / \mathrm{etc} .\end{array}$ & $\begin{array}{l}\text { Opoponax 56, 82, 89, } \\
106,107,121,170 \\
262,270\end{array}$ & $\begin{array}{l}\text { Diurético, } \\
\text { Analgésico, } \\
\text { En cólico }\end{array}$ \\
\hline Papiro & Cyperus papirus & Papyrus & Papyrus & \\
\hline Papiro en cenizas & idem & $\begin{array}{l}\text { Charta combusta } 5,8 / \\
5,22,28 / 5,22,5 / 6,4 \\
3 / 6,15,1 / 6,19,2\end{array}$ & Charta combusta 114 & $\begin{array}{l}\text { Caustico, } \\
\text { Detersivo, } \\
\text { En disenteria }\end{array}$ \\
\hline $\begin{array}{l}\text { Papiro para insuflar } \\
\text { medicinas }\end{array}$ & Idemi & $\begin{array}{l}\text { Papyrus intortus } 5,28 \text {, } \\
12 \mathrm{~K}\end{array}$ & - & $\begin{array}{l}\text { Aplicador de remedios } \\
\text { en fistulas }\end{array}$ \\
\hline Pastinaca o Chirivia & Pastinaca sativa & $\begin{array}{l}\text { Pastinaca } 2,26,2 / 4,16 \text {. } \\
2 /\end{array}$ & - & $\begin{array}{l}\text { Entermedades del } \\
\text { bazo }\end{array}$ \\
\hline Peonia & Paeonia officinalis & - & Paeonia, Glycisida 166 & Antidoto mord. serp. \\
\hline Pepino & Cuccumis sativus & $\begin{array}{l}\text { Cucumis } 4,17,21 \\
5,28,118 /\end{array}$ & $\begin{array}{l}\text { Cucumis 147, 148, } 152 \\
189\end{array}$ & $\begin{array}{l}\text { Antinntlamatorio, } \\
\text { Analgésico en vejiga }\end{array}$ \\
\hline Peral & Pirus communis & $\begin{array}{l}\text { Pira (TArentina, Signina) } \\
4,26,5 / 5,27,12 \mathrm{C} / 6,13,4 /\end{array}$ & $\begin{array}{l}\text { Pira: Crustumina y } \\
\text { Signina } 104\end{array}$ & $\begin{array}{l}\text { Antidoto contra setas } \\
\text { venenosas, Analgesico }\end{array}$ \\
\hline Perejil & Petroselinum sativum & $\begin{array}{l}\text { Petroselinum } 4,21,2 / 5 \\
23,1 \mathrm{~B} / 5,23,3 / 5,25,12\end{array}$ & $\begin{array}{l}\text { Petroselinum 106, 120, } \\
126,144,145,152,176 \\
177\end{array}$ & $\begin{array}{l}\text { Antidoto, } \\
\text { Analgésico (cólico), } \\
\text { Ent. higado y bazo }\end{array}$ \\
\hline Peucédano o Servato & Peucedanum officinale & $\begin{array}{l}\text { Peucedanum } 5,18,29 / \\
6,9,3 /\end{array}$ & $\begin{array}{l}\text { Peucedanum 56, } 163 \\
166\end{array}$ & $\begin{array}{l}\text { Antirreumático, } \\
\text { Antidoto mord. serp., } \\
\text { Evita mordeduras }\end{array}$ \\
\hline $\begin{array}{l}\text { Pimienta (blanca, } \\
\text { negra, larga y redonda) }\end{array}$ & $\begin{array}{l}\text { Piper (alba, nera, } \\
\text { longus, rotundus) }\end{array}$ & $\begin{array}{l}\text { Piper (aiba, nera, } \\
\text { longus, rotundus) } 3,12, \\
4 / 3,16,2 / 4,6,3 / 4,7,3 / 4, \\
15,3 / \text { elc. }\end{array}$ & $\begin{array}{l}\text { Piper (alba, nera, longus, } \\
\text { rotundus) } 26,32,36,70 \text {, } \\
\text { elc. }\end{array}$ & $\begin{array}{l}\text { Diurético, Erosivo, } \\
\text { Estornutatorio, } \\
\text { Cáustico, }\end{array}$ \\
\hline Pinastro & Pinus cembra & - & Taeda 58 & $\begin{array}{l}\text { Espátula para preparar } \\
\text { analgésico dentra! }\end{array}$ \\
\hline Pino & Pinus pinaster & $\begin{array}{l}\text { Pinus } 3,27,4 \mathrm{~B} / 4,15,3 / \\
4,17,2 / 4,28,2 / 5,4 / 5,5 / \\
5,12 / 5,14 / \text { etc. }\end{array}$ & Pinus $143,147,189$ & $\begin{array}{l}\text { Antitusigeno, } \\
\text { Antinflamatorio, } \\
\text { Erosivo, Emoliente }\end{array}$ \\
\hline Plantago o Llantén & Plantagus mayor & $\begin{array}{l}\text { Plantagus } 3,22,13 / 4,11 \\
6 / 4,23,2 / 6,18,10 /\end{array}$ & $\begin{array}{l}\text { Plantagus 21, 31, 83, } \\
86,158\end{array}$ & $\begin{array}{l}\text { Hemostático, Diuretico, } \\
\text { Anticatarral, }\end{array}$ \\
\hline Plátano & $\begin{array}{l}\text { Piluilas cupressio } \\
\text { Facies pilulla }\end{array}$ & - & Platanus 2 & $\begin{array}{l}\text { Analgésico en } \\
\text { cefaleas }\end{array}$ \\
\hline Polio o Zamarilla & Teucrium polium & $\begin{array}{l}\text { Polium, Trixago } 5,27,7 / \\
5,27,10 /\end{array}$ & Polium, Tiniaria 83,177 & $\begin{array}{l}\text { Analgésico, } \\
\text { Hemostático, } \\
\text { Antitusigeno, }\end{array}$ \\
\hline Polipodio & Polypodium vulgare & Filicula $2,12 \mathrm{~A} / 5,26,35 \mathrm{Cl}$ & - & Atractivo \\
\hline Portulaca & Portulaca oleracea & $\begin{array}{l}\text { Portulaca } 4,16,3 / 4,22,2 / \\
6,6,381\end{array}$ & Portulaca 53, 158 & $\begin{array}{l}\text { Erosivo, Antigotoso, } \\
\text { Diurético. }\end{array}$ \\
\hline Puerro & Allium porrum & $\begin{array}{l}\text { Porrum } 3,21,11 / 3,27 \\
4 C / 4,10,3 / 4,11,6 / 4,13 \\
4 / 4,17,1 / \text { etc }\end{array}$ & - & $\begin{array}{l}\text { Diurético, } \\
\text { Hemostático, } \\
\text { Escarizante }\end{array}$ \\
\hline
\end{tabular}


FÁRMACOS ORIGEN VEGETAL (Continuación)

\begin{tabular}{|c|c|c|c|c|}
\hline Español & Cientifico & En Celso & En Escribonio & Indicaciones \\
\hline Rábano & Raphanus sativus & $\begin{array}{l}\text { Radix, Radicula 4,12, } \\
\text { 10/5,5,2/5,27,9/5,27, } \\
12 \mathrm{C} / 6,7,7 \mathrm{C} / 6,7,8 \mathrm{~B} /\end{array}$ & Edulis 60 & $\begin{array}{l}\text { Diurético, Emético, } \\
\text { Analgésico dental, } \\
\text { Detersivo }\end{array}$ \\
\hline Rabano Rusticano & Cochlearia armoracia & Armoracia 4,16,2l & - & Enfermedades del bazo \\
\hline Rabano silvestre & Raphanus raphanistrum & Lapsanum 2,25,2/2,3/ & - & Diurético \\
\hline Regaliz & Glycirriza echinata & $\begin{array}{l}\text { Radix dulcis } 5,20,6 / \\
5,23,1 \mathrm{~B} / 6,10,1 /\end{array}$ & Glycyrrhiza 75,86 & $\begin{array}{l}\text { Antidoto, } \\
\text { Hemostático, Enf. } \\
\text { de la piedra }\end{array}$ \\
\hline Retama & Ver Aspalato & & & \\
\hline Ricino & Ricinus communis & $\begin{array}{l}\text { Cicinum (oleum), } \\
\text { Ricinus, Trixis } 5,19,6 / \\
5,24,31\end{array}$ & - & $\begin{array}{l}\text { Emoliente, } \\
\text { Vulnerario }\end{array}$ \\
\hline Romero & Rosmarinus officinale & $\begin{array}{l}\text { Rosmarinus, Cachry, } \\
5,18,51\end{array}$ & Cachry 70, 165, 255 & $\begin{array}{l}\text { Emoliente, } \\
\text { Antíinflamatorio, } \\
\text { Antidoto mord. serp. }\end{array}$ \\
\hline Rosal & Rosa Gaelica & $\begin{array}{l}\text { Rosa } 3,21,7 / 4,27,1 \mathrm{D} / \\
5,11 / 5,15 / 5,18,35 / 5 \\
19,7 / \text { etc. }\end{array}$ & $\begin{array}{l}\text { Rosa aridae } 1,3,31,36 \\
56,92,144,158 \text {, etc. }\end{array}$ & $\begin{array}{l}\text { Emoliente, } \\
\text { Antiinflamatorio, } \\
\text { Antigotoso, }\end{array}$ \\
\hline Rosal silvestre & Rosa canina & - & Rosa canina, 85 & Hemostático \\
\hline Ruda común & Rutra graveolens & $\begin{array}{l}\text { Ruta } 3,20,4 / 4,12,2 / 4 \\
13,5 / 5,4 / 5,5,2 / 5,10 / 5 \\
15 / 5,16 / \text { etc. }\end{array}$ & $\begin{array}{l}\text { Ruta 2, 5, 121, 192, 198, } \\
245\end{array}$ & $\begin{array}{l}\text { Erosivo, } \\
\text { Emoliente, } \\
\text { Escarizante }\end{array}$ \\
\hline Ruda silvestre & Ruta angustitolia & Ruta seivatica $5,27,5 \mathrm{~B}$ & $\begin{array}{l}\text { Ruta slevatici } 117,165, \\
170,177\end{array}$ & $\begin{array}{l}\text { Antidoto, } \\
\text { En lleo }\end{array}$ \\
\hline Ruibarbo & Rheum Ponticum & Radix Pontica $5,23,3 \mathrm{~B}$ / & 一 & Antidoto \\
\hline Sabina & Juniperus sabina & - & Sabina, Brathy 154 & Antirreumático \\
\hline Sagapeno & Ferula Persica & $\begin{array}{l}\text { Sagapenum } 5,23,3 / \\
6,6,25 \mathrm{~A}\end{array}$ & $\begin{array}{l}\text { Sagapenum 569, 106, } \\
107,170\end{array}$ & $\begin{array}{l}\text { Antidoto, Analgésico, } \\
\text { En el cólico } \\
\end{array}$ \\
\hline Sambuco & Sambucus nigra & - & Sambucus 160 & Antigotoso \\
\hline Saponaria & Saponaria officinalis & $\begin{array}{l}\text { Struthi } 5,18,2 / 5,22,8 / \\
6,5,3 /\end{array}$ & Struthion 10 & $\begin{array}{l}\text { Emoliente, } \\
\text { Estornutatorio, } \\
\text { Analgésico celaleas }\end{array}$ \\
\hline Satureia & Ver Ajedrea de jardin & & & \\
\hline Sauce & Salix alba & Salix 6,18,10/ & Salix 252 & $\begin{array}{l}\text { Detersivo, } \\
\text { En la sarna }\end{array}$ \\
\hline Saxilraga & Saxitraga granulata & Silis $5,23,1 \mathrm{~B} / 5,23,3 /$ & Seselis 121,126 & $\begin{array}{l}\text { Antidoto, Diurético, } \\
\text { En cólico, Ent. bazo }\end{array}$ \\
\hline Serbal & Sorbus domestica & Sorbus $2,30,3 / 4,26,8$ & Sorbus 111,121 & $\begin{array}{l}\text { Antidiarréico, En cólico } \\
\text { y ent. gástricas }\end{array}$ \\
\hline $\begin{array}{l}\text { Serpillo, Serpol o } \\
\text { Tomillo silvestre }\end{array}$ & Thymus serpyllum & $\begin{array}{l}\text { Serpylium, Serpullum } \\
3,10,2 / 4,16,3 / 5,11 /\end{array}$ & Serpiltum 1,5, 165, 166 & $\begin{array}{l}\text { Antiinflamatorio, } \\
\text { Antídoto mord. serp. }\end{array}$ \\
\hline Sésamo & $\begin{array}{l}\text { Sesamum } \\
\text { Indicum }\end{array}$ & $\begin{array}{l}\text { Sesamum } 4,15,3 / 5,15 / \\
5,18,27 /\end{array}$ & - & Emoliente \\
\hline Sicomoro & Ver Higuera Egipcia & & & \\
\hline $\begin{array}{l}\text { Solano, Dulcamara, } \\
\text { Estricno, Hierba Mora }\end{array}$ & Solanum nigrum & $\begin{array}{l}\text { Solanum o Strychnos } \\
5,26,33 A / 6,17,1 / 2,33 \\
2 / 3,18,9\end{array}$ & $\begin{array}{l}\text { Solanum } 53,83,158, \\
244,246\end{array}$ & $\begin{array}{l}\text { Detersivo, } \\
\text { Analgésico, } \\
\text { En hemoptisis }\end{array}$ \\
\hline
\end{tabular}


FÁRMACOS ORIGEN VEGETAL (Continuación)

\begin{tabular}{|c|c|c|c|c|}
\hline Español & Cientifico & En Ceiso & En Escribonio & Indicaciones \\
\hline $\begin{array}{l}\text { Tamariz, Tamarisco, } \\
\text { Taray }\end{array}$ & Tamarix Gallica & Tamarix $2,33,41$ & Tamaricum 128,132 & $\begin{array}{l}\text { En enfermedades del } \\
\text { bazo }\end{array}$ \\
\hline $\begin{array}{l}\text { Tamus, Uvaas } \\
\text { Taminias o Nueza negra }\end{array}$ & Tamus communis & $\begin{array}{l}\text { Uva taminia } 3,21,130 / \\
5,4 / 5,5,2 / 5,6,2 / 5,8 / 5,27 \\
1 / 5,11 / 5,15 /\end{array}$ & Tamno 248 & $\begin{array}{l}\text { Diuréitco, Erosivo, } \\
\text { Caustico, Detersivo }\end{array}$ \\
\hline Tapsia & Thapsia garganica & Thapsia 5, 18,24/6,4,3/ & Thapsia 230 & Vulnerario, Analgésico \\
\hline Terebinto (Resina de) & Pistacia terebinthus & $\begin{array}{l}\text { Terebinthus } 3,22,14 / 4 \\
8,3 / 5,4 / 5,5 / 5,6 / 5,12 / \text { etc }\end{array}$ & $\begin{array}{l}\text { Terebinthus } 56,75,82 \text {, } \\
173,201\end{array}$ & $\begin{array}{l}\text { Detersivo, Erosivo, } \\
\text { Antidoto, Epispástico }\end{array}$ \\
\hline Tomillo Común & Thymus vulgaris & $\begin{array}{l}\text { Thymum } 4,4 / 4,7,3 / 4 \text {, } \\
15,3 / 4,16,3 /\end{array}$ & Thymus 15,166 & $\begin{array}{l}\text { Diurético, } \\
\text { Antintlamatorio, } \\
\text { Antidoto }\end{array}$ \\
\hline Torvisco & Daphne Cnidium & $\begin{array}{l}\text { Coccum Cnidium } 5,5 \text {. } \\
2 / 5,8 / 5,18,7 \mathrm{~B} /\end{array}$ & - & $\begin{array}{l}\text { Detersivo, Cáustico, } \\
\text { Emoliente }\end{array}$ \\
\hline Tragacanto (Goma de) & Astragalus gummifer & $\begin{array}{l}\text { Tragacantha } 4,9,2 / 5 \\
13 /\end{array}$ & $\begin{array}{l}\text { Tragacantha } 27,73,74, \\
75,79,86,89, \text { etc. }\end{array}$ & $\begin{array}{l}\text { Excipiente, } \\
\text { Antitusigeno, } \\
\text { Cicatrizante, }\end{array}$ \\
\hline Trébol & $\begin{array}{l}\text { Trifolium } \\
\text { Praetense }\end{array}$ & $\begin{array}{l}\text { Trifolium 4, 16,3/5,27, } \\
7 /\end{array}$ & - & $\begin{array}{l}\text { Antidoto mord. serp. } \\
\text { Entermedades del bazo }\end{array}$ \\
\hline Trebol hediondo & Ver Higueruela & & & \\
\hline Trigo & Trigum sativum & $\begin{array}{l}\text { Triticum } 2,33,5 / 5,10 \text { I } \\
5,18,19 / 6,18,6 \mathrm{~A} 7,19,10 /\end{array}$ & Triticum 179 & $\begin{array}{l}\text { Excipiente, Escanizante, } \\
\text { Emoliente. }\end{array}$ \\
\hline Valeriana & \begin{tabular}{|l|} 
Valeriana \\
Dioscorides officinalis
\end{tabular} & - & $\begin{array}{l}\text { Phu o Saliunca } 170 \text {, } \\
176,177\end{array}$ & Antidoto \\
\hline Verbena & Verbena officinalis & $\begin{array}{l}\text { Verbena } 3,18,8 / 4,22 \\
2 / 4,23,1 / 4,31,765,28 \\
6 \mathrm{~A} 6,15,2 / 6,18,8 \mathrm{~A} / \mathrm{etc}\end{array}$ & Verbena 142,205 & $\begin{array}{l}\text { Antiinflamatorio, } \\
\text { Cicatrizante, } \\
\text { Analgésico }\end{array}$ \\
\hline Vid & Vitis vinifera & $\begin{array}{l}\text { Vitis, uva } 6,7,7 \mathrm{C} / 8,4 \text {, } \\
19 /\end{array}$ & $\begin{array}{l}\text { Vitis } 56,65,74,176, \\
233\end{array}$ & $\begin{array}{l}\text { Refrescante, } \\
\text { Excipiente, Analgésico }\end{array}$ \\
\hline Vid (Zarzillos) & & Vitis capreoli $2,33,1$ & Vitis capreoli 193 & $\begin{array}{l}\text { Repercusivo, } \\
\text { Refrescante, Antidoto }\end{array}$ \\
\hline Vid alba o Clemátide & Clematis vitalba & Vitis alba 5,2 & $\begin{array}{l}\text { Bryonia es la raiz de la } \\
V \text {. alba } 79,134,165\end{array}$ & $\begin{array}{l}\text { Diurético, } \\
\text { Antidoto mord. serp. } \\
\text { Cáustico, Diurético }\end{array}$ \\
\hline Violeta & Viola odorata & Viola purpurea 5,11 & - & $\begin{array}{l}\text { Antïnflamatorio, } \\
\text { Expectorante }\end{array}$ \\
\hline $\begin{array}{l}\text { Violeta blanca } \\
\text { (Alneli blanco) } \\
\end{array}$ & Matthiola incana & $\begin{array}{l}\text { Flos albae violae } 4,27 \\
\text { 1D/5,4/5,11/ }\end{array}$ & - & $\begin{array}{l}\text { Erosivo, } \\
\text { Antiinflamatorio }\end{array}$ \\
\hline Yezgo o Ebulo & Sambucus ebulus & - & Ebulus 153 & $\begin{array}{l}\text { Diurético, } \\
\text { Entermedades del bazo }\end{array}$ \\
\hline Zanahoria & Daucus carola sativa & - & $\begin{array}{l}\text { Daucus } 6,117,121, \\
126,144,145,152,176\end{array}$ & $\begin{array}{l}\text { Analgésico, Diurético, } \\
\text { En el cólico }\end{array}$ \\
\hline Zanahoria Cretense & Athamintas Cretensis & $\begin{array}{l}\text { Daucus Creticus } 5,23 \text {. } \\
\text { 38/ }\end{array}$ & Daucus Creticus 177 & Antidoto \\
\hline Zarza & Rubus fructicosus & - & Cauliculus 113,128 & $\begin{array}{l}\text { Enfermedades del bazo, } \\
\text { disenteria y cólico }\end{array}$ \\
\hline Zumaque & Rhus coriaria & Rhus Siriacum $6,11,5$ & $\begin{array}{l}\text { Rhus Siriacum 111, } 113, \\
142,256\end{array}$ & $\begin{array}{l}\text { Astringente local y } \\
\text { general. } \\
\text { Ent. intesinales etc. }\end{array}$ \\
\hline
\end{tabular}


FÁRMACOS ORIGEN MINERAL.

\begin{tabular}{|c|c|c|c|c|}
\hline Español & Composición & En Celso & En Escribonio & Indicaciones \\
\hline Agua de lluvia & $\mathrm{H} 2 \mathrm{O}$ & $\begin{array}{l}\text { Aqua pluviatitis } 4,19,4 / 6 \\
6,6 / 6,6,7 / 6,6,9 / 6,6,12 / 6 \\
16 \mathrm{~B} / 6,9,3 / 7,3,3 /\end{array}$ & $\begin{array}{l}\text { Aqua pluviatilis } 22,24 \text {, } \\
27,28,32,34,35\end{array}$ & Excipiente en colirios \\
\hline Agua de mar & & $\begin{array}{l}\text { Aqua maris } 4,24,2 / 4, \\
31,4 / 5,19,28 /\end{array}$ & $\begin{array}{l}\text { Aqua maris } 160,162, \\
185\end{array}$ & $\begin{array}{l}\text { Vermitugo, Antigotoso, } \\
\text { Vulnerario }\end{array}$ \\
\hline Agua ferrosa & $\begin{array}{l}\text { Agua en que se } \\
\text { introduce un hierro al } \\
\text { rojo }\end{array}$ & Aqua ferrum $4,16,2$ & Aqua ferrum 146 & $\begin{array}{l}\text { Entermedades de } \\
\text { bazo y vejiga }\end{array}$ \\
\hline Alumbre & Sales de aluminio & $\begin{array}{l}\text { Alumen } 5,31,5 / 5,2 / 5,4 / \\
5,7 / 5,18,12 / 5,19,11 / \text { etc. }\end{array}$ & Alumen 77,211 & $\begin{array}{l}\text { Erosivo, Apertivo, } \\
\text { Cicatrizante, Emoliente }\end{array}$ \\
\hline Alumbre de Melos & $\begin{array}{l}\text { Procedente de esta } \\
\text { isla del Egeo }\end{array}$ & Alumen Melini 5,1/ & Alumen Melini 226 & $\begin{array}{l}\text { Hemostático, } \\
\text { Cáustico (condiloma) }\end{array}$ \\
\hline Alumbre Egipcio & & A. Aegupti $5,28,121 /$ & A.Aegyptii 47 & $\begin{array}{l}\text { Cicatizante (fistulas), } \\
\text { En tumores de vejiga }\end{array}$ \\
\hline Alumbre filamentoso & & - & $\begin{array}{l}\text { Alumen fissi } 4,31,41, \\
42,58,61,63,65,70,71, \\
72 \text {, etc. }\end{array}$ & $\begin{array}{l}\text { Antiinflamatorio, } \\
\text { Emoliente, Cáustico }\end{array}$ \\
\hline Alumbre Frigio & De Frigia (Capadocia) & $\begin{array}{l}\text { Lapis Phrigius 5,7/ } \\
6,6,30 /\end{array}$ & & $\begin{array}{l}\text { Antiinflamatorio } \\
\text { (ocular), Erosivo }\end{array}$ \\
\hline Alumbre liquido & Sulfato y silicato de Al & A. Liquidum $5,2 / 5,6$ / & $\begin{array}{l}\text { Al. Liquidum 86, 227, } \\
243\end{array}$ & $\begin{array}{l}\text { Hemostático, } \\
\text { Vutnerario, Erosivo }\end{array}$ \\
\hline Alumbre Redondo & En torma granular & $\begin{array}{l}\text { Alumen rotundum } 5,12 / \\
5,18,11 / 5,19,7 / 5,19,8 / \\
5,19,15 / 6,18,19 / \\
\end{array}$ & $\begin{array}{l}\text { Alumen rotundum } 30 \text {, } \\
203,205,206,208 \text {, } \\
248\end{array}$ & $\begin{array}{l}\text { Epispástico, } \\
\text { Emoliente, } \\
\text { Cicatrizante }\end{array}$ \\
\hline Alumbre Scissile & Alumbre en pluma & $\begin{array}{l}\text { Scissite o Squistum } 5,2 / \\
5,7 / 5,8 / 5,18,11 / 5,19,6 / \\
5,19,15 / 5,19,19,17 / \text { etc. }\end{array}$ & - & $\begin{array}{l}\text { Caustico, Erosivo, } \\
\text { Cicatrizante, } \\
\text { Emoliente }\end{array}$ \\
\hline Ammoniacum (Sal de) & $\begin{array}{l}\text { Cloruro sodico, con } \\
\text { cloruros de } \mathrm{Ca} \text { y } \mathrm{Mg}\end{array}$ & $\begin{array}{l}\text { Ammoniacum salis } 5 \text {, } \\
18,2 / 5,18,7 \mathrm{~B} / 5,18,14 \mathrm{~B} / \\
5,18,16 / 5,19,14 / \text { etc. }\end{array}$ & $\begin{array}{l}\text { Ammoniacum salis } 45 \\
50,175,203,208,248\end{array}$ & $\begin{array}{l}\text { Emoliente, Atractivo, } \\
\text { Madurativo }\end{array}$ \\
\hline $\begin{array}{l}\text { Antimonio o Kohl } \\
\text { arábigo }\end{array}$ & Sulfuro de antimonio & $\begin{array}{l}\text { Stibium } 5,15 / 5,19,28 / 5 \\
20,5 / 6,6,5 B / 6,6,6 / 6,6 \\
8 / 6,6,12 / \text { etc. }\end{array}$ & Stibium $23,24,27,34$ & $\begin{array}{l}\text { Esmoliente, } \\
\text { Cicatrizante, } \\
\text { Cáustico }\end{array}$ \\
\hline Arcilla & $\begin{array}{l}\text { Silicatos de Al y otros } \\
\text { compuestos }\end{array}$ & - & Argila 76 & Antidisneico \\
\hline Arcilla de cerramista & $\begin{array}{l}\text { Silicatos de Al. Celso } \\
\text { dice que = Creta } \\
\text { cimolada }\end{array}$ & Creta figularis $5,1 /$ & - & Hemostático \\
\hline Arsenico & Ver Oropimento & & & \\
\hline Atramentum scriptorium & Tinta hecha con hollin & $6,4,31$ & - & En alopecia \\
\hline Azufre & Azulre sin calentar & $\begin{array}{l}\text { Sulphur o Apyron } 3 \\
27,2 \mathrm{C} / 4,3,3 / 4,8,3 / 4 \\
27,1 \mathrm{D} / 5,3 / 5,4 / 5,5,2 / \text { etc. }\end{array}$ & Sulphur $250,253,254$ & $\begin{array}{l}\text { Madurativo, Erosivo, } \\
\text { Detersivo, } \\
\text { Antiinflamatorio }\end{array}$ \\
\hline Azufre "vivo" & Azutre sublimado & - & $\begin{array}{l}\text { Sulphur vivi } 78,95,231 \text {, } \\
246,251\end{array}$ & $\begin{array}{l}\text { Andidisnéico, } \\
\text { Antitusigeno, En sarna }\end{array}$ \\
\hline Azufre calentado & $\begin{array}{l}\text { "Preparatum" para } \\
\text { impregnar lana }\end{array}$ & $\begin{array}{l}\text { Lana sulphurata } 4,12, \\
4 / 4,13,3 /\end{array}$ & Lana sulphurata 43 & $\begin{array}{l}\text { Cicatrizante (oido), } \\
\text { Dolor e inflamación } \\
\text { gástricos }\end{array}$ \\
\hline
\end{tabular}


FÁRMACOS ORIGEN MINERAL (Continuación)

\begin{tabular}{|c|c|c|c|c|}
\hline Español & Composición & En Celso & En Escribonio & Indicaciones \\
\hline Basura de gimnasio & $\begin{array}{l}\text { Residuos de frotar la } \\
\text { piel con ceraio }\end{array}$ & $\begin{array}{l}\text { Sordes ex gymnasio } \\
5,11 / 5,15 /\end{array}$ & - & $\begin{array}{l}\text { Emoliente, } \\
\text { Antinfllamatorio }\end{array}$ \\
\hline Betün & $\begin{array}{l}\text { Compuestos naturales } \\
\text { de } \mathrm{C} \text { e H de olor } \\
\text { especial }\end{array}$ & $\begin{array}{l}\text { Bitumen } 3,27,2 \mathrm{C} / 5,3 / \\
5,11 / 5,19,6 / 5,19,20 / 5 \\
20,1 \mathrm{~B} / 6,9,5 /\end{array}$ & Bitumen $40,52,54$ & $\begin{array}{l}\text { Antiinffamatorio, } \\
\text { Madurativo, } \\
\text { Vulnerario }\end{array}$ \\
\hline $\begin{array}{l}\text { Betun de Judea o } \\
\text { Asfalto }\end{array}$ & $\begin{array}{l}\text { Natural en grandes } \\
\text { depositos del Mar } \\
\text { Muerto }\end{array}$ & - & $\begin{array}{l}\text { Bitumen ludaicus } 207 \text {, } \\
209\end{array}$ & $\begin{array}{l}\text { Analgésico, } \\
\text { Vulneario }\end{array}$ \\
\hline Betún de Sagunto & $\begin{array}{l}\text { Natural en las } \\
\text { proximidades de esta } \\
\text { ciudad }\end{array}$ & - & Bitumen Saguntinus 208 & $\begin{array}{l}\text { Analgesico, } \\
\text { Vuínerario }\end{array}$ \\
\hline Brea, Fior de & $\begin{array}{l}\text { Vapor, recogido en } \\
\text { lana, de cocer la brea }\end{array}$ & - & $\begin{array}{l}\text { Fiorem picis, pisselaion } \\
40\end{array}$ & Antiintlamatorio \\
\hline Cadmia & Oxido de $\mathrm{Zn}$ y $\mathrm{Cd}$ & $\begin{array}{l}\text { Cadmia } 5,7 / 5,22,1 / 5,28 \\
5 / 5,28,121 / 5,28,16 \mathrm{~B} / 6,6 \\
5 \mathrm{~B} / 6,6,6 / \text { elc }\end{array}$ & Cadmia 21, 220, 242 & $\begin{array}{l}\text { Erosivo, Emoliente, } \\
\text { Cáustico }\end{array}$ \\
\hline Cai viva & Oxido de calcio & $\begin{array}{l}\text { Calx viva } 5,6,215,7,8 / 5, \\
18,1215,18,2015,18,25 i \\
\text { etc. } \\
\end{array}$ & $\begin{array}{l}\text { Calx viva } 114,228,230, \\
239\end{array}$ & $\begin{array}{l}\text { Erosivo, } \\
\text { Cáustico }\end{array}$ \\
\hline Calamina & $\begin{array}{l}\text { Calentado en agua la } \\
\text { cadmia }\end{array}$ & $\begin{array}{l}\text { Cadmia eloate } 6,6,6 / 6 \\
6,21 / 6,6,25 \mathrm{~A} / 6,6,25 \mathrm{~B} / \\
6,6,25 \mathrm{C} / 6,6,27 \mathrm{~B} / \\
\end{array}$ & - & En colirios \\
\hline Carbón mineral & $\begin{array}{l}\text { Carbón, Piedra negra } \\
\text { que se obtenia en } \\
\text { Cagas (Licia) } \\
\end{array}$ & Cinis aequis $5,28,16 \mathrm{Cl}$ & $\begin{array}{l}\text { Carbo: } 37,59,60 \\
\text { Gagates lapis } 225\end{array}$ & $\begin{array}{l}\text { Analgésico dental, } \\
\text { En Sarna, } \\
\text { Erosivo (gagates) }\end{array}$ \\
\hline Cenizas de madera & & Cinis $5,6,2 / 25,7 / 6,6,22$ & Cinis 232 & $\begin{array}{l}\text { Erosivo, Exedente, } \\
\text { En Prolapso rectales }\end{array}$ \\
\hline Cinabrio o Minio & $\begin{array}{l}\text { Sulturo rojo de } \\
\text { Mercurio }\end{array}$ & \begin{tabular}{|l|} 
Minium $4,22,4 / 5,5,2 / 5$ \\
$6 / 5,19,21 / 5,19,25 / 5,20$ \\
$3 / 6,6,18 / 6,8,2 B / 6,19,26 /$ \\
\end{tabular} & - & $\begin{array}{l}\text { Purgante, } \\
\text { Antiunflamatorio, } \\
\text { Erosivo } \\
\end{array}$ \\
\hline Cobre quemado & Mineral de Cu calcinado & $\begin{array}{l}\text { Aes combusto } 5,6 / 5,15 / \\
5,19,7 / 5,19,8115,19,11 \mathrm{~B} / \\
\text { etc. }\end{array}$ & $\begin{array}{l}\text { Aes combusto 27, 36, } \\
51,72\end{array}$ & $\begin{array}{l}\text { Erosivo, Emoliente, } \\
\text { Madurativo }\end{array}$ \\
\hline Cobre, Cardenillo de & $\begin{array}{l}\text { Subacetato y carbonato } \\
\text { de cobre }\end{array}$ & $\begin{array}{l}\text { Aerugo } 5,2 / 5,5 / 5,6 / 5,7 / 1 \\
5,8 / 5,9 / 5,16 / 5,18,2 / 5 \\
19,1 / \text { etc. } \\
\end{array}$ & $\begin{array}{l}\text { Aerugo } 34,35,36,49 \\
203,205,206,207,208, \\
209\end{array}$ & $\begin{array}{l}\text { Cicatrizante, } \\
\text { Detersivo, Erosivo, } \\
\text { Corrosivo }\end{array}$ \\
\hline Cobre, Crisocolla & $\begin{array}{l}\text { Borato, silicato y } \\
\text { carbonato de } \mathrm{Cu} \\
\end{array}$ & $\begin{array}{l}\text { Chrysocolla } 5,6,2 / 5,7 / \\
5,8 / 5,20,3 !\end{array}$ & - & $\begin{array}{l}\text { Corrosivo, Cáustico, } \\
\text { Erosivo }\end{array}$ \\
\hline Cobre, Difriges & $\begin{array}{l}\begin{array}{l}\text { Sulfuro y oxido de } \mathrm{Cu} \\
\text { y } \mathrm{Fe}\end{array} \\
\end{array}$ & $\begin{array}{l}\text { Diphyges } 5,7 / 5,8 / 5,22, \\
2 \mathrm{C} / 6,9,37 \mathrm{D} /\end{array}$ & Diphryges 227, 247 & $\begin{array}{l}\text { Cáustico, Corrosivo } \\
\text { suave }\end{array}$ \\
\hline Cobre, Estomoma & Oxido rojo de $\mathrm{Cu}$ & Stomoma $6,6,5$ & - & Hemostático \\
\hline Cobre, Flor de & Oxido rojo de Cobre & $\begin{array}{l}\text { Flor aeris o Chalcantus } \\
3,715,915,20,1 / \\
\end{array}$ & $\begin{array}{l}\text { Flor aeris } 34,45,63, \\
71,198,227,230,240\end{array}$ & $\begin{array}{l}\text { Corrosivo, } \\
\text { Escarificante }\end{array}$ \\
\hline Cobre, metal & & - & $\begin{array}{l}\text { Aes, Cuprum 23, 36, } \\
\text { 206. 239, }\end{array}$ & Cáustico, Anticatarral \\
\hline $\begin{array}{l}\text { Cobre, Mineral de, } 0 \\
\text { Vitriolo }\end{array}$ & $\begin{array}{l}\text { Carbonato y sulfatos } d e \\
\mathrm{Cu}\end{array}$ & $\begin{array}{l}\text { Calcitis } 5,1 / 5,2 / 5,5,2 / \\
5,6 / 5,7 / 5,8 / 5,12 / 5,18,7 / \\
5,19,15 / 5,20,1 / \text { etc. }\end{array}$ & $\begin{array}{l}\text { Chalcitis } 37,47,226, \\
231,240,288\end{array}$ & $\begin{array}{l}\text { Hemostático, } \\
\text { Cicatrizante. } \\
\text { Cauustico }\end{array}$ \\
\hline
\end{tabular}


FÁRMACOS ORIGEN MINERAL (Continuación)

\begin{tabular}{|c|c|c|c|c|}
\hline Españo! & Composición & En Celso & En Escribonio & Indicaciones \\
\hline Cobre. Escama de & Oxido negro de Cobre & $\begin{array}{l}\text { Squama aeris } 5,1 / 5,5, \\
2 / 5,6 / 5,7 / 5,8 / 5,18,11 / \\
\text { etc. }\end{array}$ & $\begin{array}{l}\text { Squama aeris } 51,133 \\
201,202,213,227,237\end{array}$ & $\begin{array}{l}\text { Hemostático, } \\
\text { Cicatrizante, Cáustico }\end{array}$ \\
\hline Creła Cimolada & $\begin{array}{l}\text { De Cimolus en las Islas } \\
\text { Cicladas }\end{array}$ & $\begin{array}{l}\text { Creta Cimolia } 2,33,2 / 3, \\
19,2 / 5,1 / 5,26,33 A / 5,27, \\
13 \mathrm{~B} / 6,5,31 /\end{array}$ & Creta Cimolia 244 & $\begin{array}{l}\text { Hemostático, } \\
\text { Antiinflamatorio, } \\
\text { En enf. renales }\end{array}$ \\
\hline Creta de Samos & $\begin{array}{l}\text { Llevaba una estrella } \\
\text { grabada, de gran pureza }\end{array}$ & $\begin{array}{l}\text { Creta Samiae,Aster 6,6, } \\
12 /\end{array}$ & $\begin{array}{l}\text { Creta astera o Samiae } \\
24,83,86,112,117,189\end{array}$ & $\begin{array}{l}\text { Antiinflamatorio, } \\
\text { Hemostático, En el lleo }\end{array}$ \\
\hline Espodium & $\begin{array}{l}\text { Calentando, en seco, la } \\
\text { cadmia }\end{array}$ & $\begin{array}{l}\text { Spodium } 5,7 / 5,13 / 5,28 \\
16 \mathrm{~B} / 6,6,3 / 6,6,4 / 6,6,5 / \\
6,6,12 / 6,6,13 / 6,7,3 \mathrm{~B} / \\
\end{array}$ & $\begin{array}{l}\text { Cadmiae ustae } 23,27, \\
33,34\end{array}$ & $\begin{array}{l}\text { Corrosivo, } \\
\text { Cicatrizante, } \\
\text { Antiinflamatorio } \\
\end{array}$ \\
\hline Estaño & & - & $\begin{array}{l}\text { Stanneus o Stagneus } \\
30,65,230,268\end{array}$ & $\begin{array}{l}\text { Vaso en donde } \\
\text { preparar receta }\end{array}$ \\
\hline Hematita & $\begin{array}{l}\text { Oxido de Fe con silicatos } \\
\text { y sulfatos de Aluminio }\end{array}$ & $\begin{array}{l}\text { Hematites } 5,5,2 / 5,7 / 6,6 \text {, } \\
21 / 6,6,30 /\end{array}$ & Hematites 26 & Detersivo, Corrosivo \\
\hline $\begin{array}{l}\text { Hierro escama } \\
\text { calentadas }\end{array}$ & Óxidos de $\mathrm{Fe}$ & Squama ferris $5,1 / 5,6,2 /$ & - & Hemostatico, Erosivo \\
\hline Hierro, Escorias de & Óxidos y silicatos de Fe & Scofia ferri $5,28,2 F$ / & Scoria ferri 188 & $\begin{array}{l}\text { Cicatrizante, } \\
\text { Antidoto (aconito) } \\
\end{array}$ \\
\hline Lejia & $\begin{array}{l}\text { Cenizas de sarmientos } \\
\text { cocidos en agua }\end{array}$ & - & $\begin{array}{l}\text { Lixiva o Lixivia 182, } \\
184,230\end{array}$ & $\begin{array}{l}\text { Antidoto, } \\
\text { Antiinflamatorio }\end{array}$ \\
\hline Litargirio de Plata & $\begin{array}{l}\text { Óxido de } \mathrm{Pb} \text { y } \mathrm{Ag} \text { al } \\
\text { calentar galena } \\
\text { argentifera }\end{array}$ & $\begin{array}{l}\text { Spuma argenti } 3,10,2 / 1 \\
3,19,2 / 5,5,2 / 5,7 / 5,11 / 5,1 \mathrm{~d} \\
7 \mathrm{~B} \text { / etc. }\end{array}$ & $\begin{array}{l}\text { Spuma argenti, } \\
\text { Litargirio } 81,183,207 \text {, } \\
209,212,213\end{array}$ & $\begin{array}{l}\text { Antiintlamatorio } \\
\text { Corrosivo, Detersivo }\end{array}$ \\
\hline Marmol calcinado & $\begin{array}{l}\text { Roca metamórica } \\
\text { cristalina }\end{array}$ & Marmoris cocti $5,22,6$ & - & Hemostático \\
\hline Misy & $\begin{array}{l}\text { Mineral desconocido, } \\
\text { aigunos lo relacionan } \\
\text { con el vitriolo }\end{array}$ & $\begin{array}{l}\text { Misy } 5,1 / 5,5,2 / 5,6 / 5,7 / \\
5,8 / 5,9 / 5,19,7 / 5,19,8 / \\
5,9,15 / \text { etc. } \\
\end{array}$ & $\begin{array}{l}\text { Misy } 34,37,42,51 \\
62,170,176,177 \\
208,223,227,228 \\
\end{array}$ & $\begin{array}{l}\text { Hemostático } \\
\text { Detersivo, Erosivo, } \\
\text { Cáustico }\end{array}$ \\
\hline $\begin{array}{l}\text { Negro de cobre } \\
\text { o creta sutoria }\end{array}$ & Calcitis y cortezas & $\begin{array}{l}\text { Atramentum sutorium } \\
5,1 / 5,2 / 5,6,2 / 5,7 / 5,8 \text { /etc. }\end{array}$ & $\begin{array}{l}\text { Atramentum sutorium } \\
208,248 \\
\end{array}$ & $\begin{array}{l}\text { Hemostático } \\
\text { cicatrizante }\end{array}$ \\
\hline Nieve & & & Nivis globulae 199 & Antidoto (sanguijuela) \\
\hline Ocre amarillo & Sulfato y óxido de $\mathrm{Fe}$ & $\begin{array}{l}\text { Ochra Attice vel Scyrice } \\
5,14\end{array}$ & - & Cicatrizante \\
\hline Ocre Rojo (de Sinope) & $\begin{array}{l}\text { Sulfatos y sulfuros de } \\
\mathrm{Fe}\end{array}$ & $\begin{array}{l}\text { Bolus rubra u Ochra } 5,7 / \\
5,8 / 5,14 / 5,18 / 5,19\end{array}$ & - & $\begin{array}{l}\text { Cicatrizante, Erosivo } \\
\text { Emoliente } \\
\end{array}$ \\
\hline Oropimento & Trisulfuro de arsénico & $\begin{array}{l}\text { Auripigmentum, } \\
\text { Arsenicon } 5,2 / 5,5 / 5,6 / \\
5,7 / 5,8 / 5,9 / 5,22,2 \mathrm{~B} / \text { etc. } \\
\end{array}$ & $\begin{array}{l}\text { Auripigmentum, } \\
\text { Arsenicon 114, } 227 \text {, } \\
230,237\end{array}$ & $\begin{array}{l}\text { Escarificante, Erosivo } \\
\text { Cáustico }\end{array}$ \\
\hline $\operatorname{Pez}$ & $\begin{array}{l}\text { Por destilación de } \\
\text { maderas de coniteras }\end{array}$ & $\begin{array}{l}\text { Pix 4,13,6/5,3/5,5,2/5,15i } \\
5,15 / 5,18,10 / 5,11,26 / \\
5,19,1 / \text { etc. } \\
\end{array}$ & $\begin{array}{l}\text { Pix } 154,157,211, \\
232,251\end{array}$ & $\begin{array}{l}\text { Madurativo, } \\
\text { Detersivo, Emoliente }\end{array}$ \\
\hline Pez con aceite & $\begin{array}{l}\text { Mezcla de ambas } \\
\text { materias }\end{array}$ & - & Passelaion 40 & En Otitis \\
\hline Pez de Brutius & $\begin{array}{l}\text { Pez de esta comarca } \\
\text { italiana }\end{array}$ & - & $\begin{array}{l}\text { Picis Bruttiae 207, 208, } \\
210\end{array}$ & $\begin{array}{l}\text { Emoliente, } \\
\text { Cicatrizante } \\
\end{array}$ \\
\hline
\end{tabular}


FÁRMACOS ORIGEN MINERAL (Continuación)

\begin{tabular}{|c|c|c|c|c|}
\hline Español & Composicion & En Celso & En Escribonio & Indicaciones \\
\hline Pez Española & & - & $\begin{array}{l}\text { Picis Hispaniae } 209 \\
256,263,266\end{array}$ & $\begin{array}{l}\text { Analgésico, } \\
\text { Antiinflamatorio }\end{array}$ \\
\hline $\begin{array}{l}\text { Pez Griega o } \\
\text { Colotonia }\end{array}$ & De Coloton, isla griega & $\begin{array}{l}\text { Colophonia } 5,19,11 \mathrm{~B} / \\
5,19,17 /\end{array}$ & $\begin{array}{l}\text { Cotophonia 137, 138, } \\
139,206,211\end{array}$ & $\begin{array}{l}\text { Madurativo, } \\
\text { Emoliente, Purgante } \\
\text { intestinal }\end{array}$ \\
\hline $\begin{array}{l}\text { Piedra de Assos o } \\
\text { Sarcofaga }\end{array}$ & $\begin{array}{l}\text { Piedra voicánica no bien } \\
\text { detinida }\end{array}$ & $\begin{array}{l}\text { Lapis Assius, } \\
\text { Sarcophagus } 3,41,7 ! \\
5,7 / 5,19,19 / 6,6,31 /\end{array}$ & Lapis Assius 82, 267 & $\begin{array}{l}\text { Antigotoso, Cáustico. } \\
\text { Emoliente }\end{array}$ \\
\hline Piedra de Licia & & Lapidis Lucii 6,6,30 & & $\begin{array}{l}\text { Antiinflamatorio } \\
\text { ocular }\end{array}$ \\
\hline Piedra de Molino & & $\begin{array}{l}\text { Lapis molaris, Pyrites } \\
5,11 / 5,18,15 / 5,18,161 \\
5,28,15 \mathrm{E}\end{array}$ & - & $\begin{array}{l}\text { Emoliente, } \\
\text { Antiinflamatorio }\end{array}$ \\
\hline Piedra Pómez & $\begin{array}{l}\text { Silicato y carbonato de } \\
\text { Al }\end{array}$ & $\begin{array}{l}\text { Pumex } 5,5 / 5,12 / 5,18,18 / \\
5,18,26 /\end{array}$ & - & $\begin{array}{l}\text { Epispático, Detersivo, } \\
\text { Emoliente }\end{array}$ \\
\hline Piedras varias & Ver Alumbre & & & \\
\hline Plata & & - & Argentum 30 & $\begin{array}{l}\text { Vaso para preparar } \\
\text { recelas }\end{array}$ \\
\hline Plomo & & - & Plumbum $80,228,230$ & $\begin{array}{l}\text { Vaso para preparar } \\
\text { recetas }\end{array}$ \\
\hline Plomo lavado & Galena lavada con agua & $\begin{array}{l}\text { Plumbum elotum } 5,6,16 \mathrm{C} / \\
5,18,27 / 5,26,36 \mathrm{~B} / 5,28,5 / \\
6,6,5 / 6,6,16 \mathrm{C} / 6,17,1 /\end{array}$ & $\begin{array}{l}\text { P. elotum, Molybdaena } \\
220\end{array}$ & $\begin{array}{l}\text { Emoliente, } \\
\text { Escarizante }\end{array}$ \\
\hline Plomo quemado & Galena calentada & $\begin{array}{l}\text { Plumbum combustum } \\
5,1 / 5,18,11 / 5,18,29 / \\
5,28,5 / 6,6,51\end{array}$ & - & $\begin{array}{l}\text { Hemostatico, } \\
\text { Emoliente }\end{array}$ \\
\hline Plomo, Cerusa & Carbonato de Plomo & $\begin{array}{l}\text { Cerussa } 3,10,2 / 4,31,7 / \\
5,19,20 / 5,19,23 / \text { elc }\end{array}$ & $\begin{array}{l}\text { Cerussa, Psimithium } \\
32,33,45,49,184 \\
207,208,217,218 y \\
\end{array}$ & $\begin{array}{l}\text { Emoliente, } \\
\text { Antinflamatorio, } \\
\text { Cicatrizante }\end{array}$ \\
\hline Plomo, Cerusa lavada & & $\begin{array}{l}\text { Cerussa elotae } 6,6,6 / \\
6,6,12 / 6,17 / \\
\end{array}$ & & En diferentes colirios \\
\hline Plomo, Escorias & $\begin{array}{l}\text { Escorias de mineral de } \\
\text { plomo }\end{array}$ & $\begin{array}{l}\text { Plumbi recrementum } \\
5,15 / 5,19,26 / 5,27,13 \mathrm{~B} \\
6,7,8 \mathrm{~A}\end{array}$ & $\begin{array}{l}\text { Plumbi stercus, Scoria } \\
48\end{array}$ & $\begin{array}{l}\text { Antiinflamatorio, } \\
\text { Emoliente }\end{array}$ \\
\hline Polvo del camino & Idem & $\begin{array}{l}\text { Pulvis ex via } 3,19,3 / \\
4,12,1 /\end{array}$ & - & $\begin{array}{l}\text { En inflamación } \\
\text { gàstrica }\end{array}$ \\
\hline Psorico & $\begin{array}{l}\text { Preparatorio de Chalcitis } \\
\text { y Cadmia }\end{array}$ & $\begin{array}{l}\text { Psoricum } 6,6,31 \mathrm{~B} \text { / } \\
6,6,33\end{array}$ & Psoricum 32 & $\begin{array}{l}\text { Antininflamatorio } \\
\text { ocular }\end{array}$ \\
\hline Sal & Cloruro sódico & $\begin{array}{l}\text { Sal } 3,21,11 / 4,22,4 / 4,29 \\
2 / 5,7 / 5,8 / 5,12 / 5,18,20 / \\
5,19,11 \mathrm{~B} / 5,21,2 / 5,22,2 \mathrm{~B} /\end{array}$ & $\begin{array}{l}\text { Sal } 68,135,136,154 \\
199,217,218\end{array}$ & $\begin{array}{l}\text { Erosivo, Emoliente, } \\
\text { Cáustico, Epispástico }\end{array}$ \\
\hline Salgema & Sal mineral & $\begin{array}{l}\text { Sal to ssile } 6,5,3 / 6,6,25 \mathrm{C} / \\
6,13,1 /\end{array}$ & Sal fossicil $59,60,206$ & $\begin{array}{l}\text { Quita manchas de pie! } \\
\text { Cáustico }\end{array}$ \\
\hline Salmuera & $\begin{array}{l}\text { Solución saturada de sal } \\
\text { en agua }\end{array}$ & Muria 4,16l & Muria 60,185 & $\begin{array}{l}\text { Analgésico dental, } \\
\text { Antidoto (coriandro) }\end{array}$ \\
\hline Sandaraca o Rejalgar & Disulturo de arsénico & $\begin{array}{l}\text { Sandaraca } 5,6 / 5,7 / 5,8 / \\
5,18,30 / 5,22,2 \mathrm{C} / \text { etc. }\end{array}$ & $\begin{array}{l}\text { Sandaraca o Pompholix } \\
26,49,72,114,220\end{array}$ & $\begin{array}{l}\text { Erosivo, Corrosivo, } \\
\text { Cáustico }\end{array}$ \\
\hline
\end{tabular}


FÁRMACOS ORIGEN MINERAL (Continuación)

\begin{tabular}{|c|c|c|c|c|}
\hline Español & Composición & En Celso & En Escribonio & Indicaciones \\
\hline Sori & $\begin{array}{l}\text { Sulfato de Fe con Cuy } \\
\mathrm{Pb}\end{array}$ & Sori $6,9,5$ & Sori 51.227 & $\begin{array}{l}\text { Cáustico (dental) } \\
\text { Antinflamatorio } \\
\text { (hemorroides) }\end{array}$ \\
\hline Sosa & $\begin{array}{l}\text { Carbonato hidratado de } \\
\mathrm{Na} \text { con Cloruros de } \mathrm{Ca}\end{array}$ & $\begin{array}{l}\text { Nitrum } 2,12 \mathrm{E} / 2,33,5 / 3,6, \\
16 / 3,23,7 / 3,27,1 \mathrm{D} / \\
6,7,7 \mathrm{~B}\end{array}$ & $\begin{array}{l}\text { Nitrum } 8,70,78,89 \\
135,153,190,196 \\
198,199,228,230\end{array}$ & $\begin{array}{l}\text { Escariolitico, } \\
\text { En Antidotos }\end{array}$ \\
\hline $\begin{array}{l}\text { Sosa espuma de, o } \\
\text { Alronitro }\end{array}$ & $\begin{array}{l}\text { Carbonato y nitrato de } \\
\mathrm{Na} \text { y K y óxidos de Cu y } \\
\mathrm{Fe}\end{array}$ & $\begin{array}{l}\text { Aphronitru, o Spuma nitri } \\
\text { nitri } 5,6 / 5,18,7 \mathrm{~B} / 5,18 \\
14 \mathrm{~B} / 5,18,18 / \mathrm{etc} \text {. }\end{array}$ & $\begin{array}{l}\text { Aphronitrum } 82,118, \\
157,161,261,263 \\
267\end{array}$ & Detersivo, Emoliente \\
\hline Sosa roja & $\begin{array}{l}\text { Sosa con sales } \\
\text { metalilicas }\end{array}$ & $\begin{array}{l}\text { Nitum rubrum } 5,18,31 / \\
5,22,4 / 5,28,18 \mathrm{~B}\end{array}$ & Nitum rubrum 216 & $\begin{array}{l}\text { Emoliente, } \\
\text { Epispástico }\end{array}$ \\
\hline Tártaro (Sal de) & $\begin{array}{l}\text { Acido de } K \text { en las } \\
\text { tinajas de mosto } \\
\text { fermentado }\end{array}$ & - & $\begin{array}{l}\text { Faecula } 82,226,228 \\
230\end{array}$ & $\begin{array}{l}\text { Caustico, } \\
\text { Antinflamatono }\end{array}$ \\
\hline Tierra de Eretria & $\begin{array}{l}\text { Silicato de Al con Fey } \\
\mathrm{Cu}\end{array}$ & $\begin{array}{l}\text { Terra Eretria 5,15/5,19, } \\
7 / 6,3,2 /\end{array}$ & - & Emoliente \\
\hline Tierra Lemnia & $\begin{array}{l}\text { Silicatos y sulfatos de } \\
\text { Al, Fe y Mg }\end{array}$ & & Terra Lemmia 170 & En Antidoto \\
\hline Tierra Samia & $\begin{array}{l}\text { Silicatos y sulfatos de } \\
\text { Al }\end{array}$ & Terra Samia 6,6,12/ & - & Antiinflamatorio (en \\
\hline Yeso & Sulfato de Ca hidratado & Gypsum $3,19.2$ & Gypsum 132,182 & $\begin{array}{l}\text { Antidiaforético, } \\
\text { En ent, de bazo }\end{array}$ \\
\hline
\end{tabular}

FÁRMACOS ORIGEN ANIMAL

\begin{tabular}{|c|c|c|c|c|}
\hline Español & Composición & En Celso & En Escribonio & Indicaciones \\
\hline Alcionio & $\begin{array}{l}\text { Celentéreo de la } \\
\text { familia del coral }\end{array}$ & $\begin{array}{l}\text { Alcyonium } 5,6,215,7 / \\
5,18,26 / 5,28,19 \mathrm{Cl}\end{array}$ & - & $\begin{array}{l}\text { Erosivo, Corrosivo, } \\
\text { Emoliente }\end{array}$ \\
\hline Anade (sangre) & & - & Anas 177,230 & $\begin{array}{l}\text { Antidoto, } \\
\text { Emoliente }\end{array}$ \\
\hline $\begin{array}{l}\text { Buey (Cuemo, bazo, } \\
\text { carne) }\end{array}$ & - & Lien bobuli 4,16,3! & Comu bobuli 39,189 & $\begin{array}{l}\text { En enfermedades } \\
\text { del bazo (lien), y } \\
\text { otalgias (cornu) }\end{array}$ \\
\hline Cabra (Epiplon, grasa) & & Sebi caprino 5,18,33 & Omentum 158 & $\begin{array}{l}\text { Emoliente en } \\
\text { padagra }\end{array}$ \\
\hline $\begin{array}{l}\text { Cabra montesa } \\
\text { (Heces) }\end{array}$ & & & Capreae montanae 127 & En ictericia \\
\hline Cantarida & Meloe vesicatoria & $\begin{array}{l}\text { Cantharidis } 5,8 / 5,22,2 \mathrm{CI} \\
5,27,12 / 5,28,18 \mathrm{~B}\end{array}$ & Cantharidis 189,231 & $\begin{array}{l}\text { Cáustico, } \\
\text { Emoliente, Tóxico, } \\
\text { Limpiador }\end{array}$ \\
\hline Caracol & $\begin{array}{l}\text { Terrestre y } \\
\text { marino }\end{array}$ & Coclea $5,215,21,6$ & Cochlea 46 & $\begin{array}{l}\text { Vuinerario } \\
\text { Antiinflamatorio, } \\
\text { En Histeria }\end{array}$ \\
\hline Castoreo & $\begin{array}{l}\text { Liquido emitido } \\
\text { por las glandulas } \\
\text { odoriferas }\end{array}$ & $\begin{array}{l}\text { Castoreum } 3,16,2 / \\
3,20,4 / 3,20,5 / 3,23,7 / \\
\text { elc. }\end{array}$ & $\begin{array}{l}\text { Castoreum } 3,5,9,23 \\
88,101,117,120,121 \\
165,166,173,175\end{array}$ & $\begin{array}{l}\text { Estimulante, } \\
\text { Antifusigeno, } \\
\text { Emoliente }\end{array}$ \\
\hline
\end{tabular}


FÁRMACOS ORIGEN ANIMAL (Continuación)

\begin{tabular}{|c|c|c|c|c|}
\hline Español & Composición & En Celso & En Escribonio & Indicaciones \\
\hline Cedria & $\begin{array}{l}\text { Pez que se } \\
\text { tomaba saiado }\end{array}$ & - & Cedria 186 & $\begin{array}{l}\text { Antidoto (liebre } \\
\text { marina) }\end{array}$ \\
\hline Cera & & $\begin{array}{l}\text { Cera } 4,31,5 / 5,11 / 5,14 / \\
\text { etc. }\end{array}$ & $\begin{array}{l}\text { Cera 82, 86, 156, 157, } \\
\text { 175, etc. }\end{array}$ & $\begin{array}{l}\text { Vulnerario, } \\
\text { Emoliente, } \\
\text { Antinflamatorio }\end{array}$ \\
\hline Cerato (Cera y aceite) & $\begin{array}{l}\text { Usado en las } \\
\text { palestras }\end{array}$ & $\begin{array}{l}\text { Ceratum } 4,8,31 \\
5,18,1 / \text { etc. }\end{array}$ & Ceratum 157 & $\begin{array}{l}\text { Vulnerario, } \\
\text { Emoliente, } \\
\text { Escarizante }\end{array}$ \\
\hline Cerda (Vulva, Grasa) & & Volva porcae 2,24 & $\begin{array}{l}\text { Volva porcae 104; } \\
\text { Sebum } 271\end{array}$ & $\begin{array}{l}\text { En dolor y acidez } \\
\text { gástricos }\end{array}$ \\
\hline $\begin{array}{l}\text { Cerdo (grasa, sangre, } \\
\text { etc.) }\end{array}$ & & - & $\begin{array}{l}\text { Porcus 187, 190, } 197, \\
221,222\end{array}$ & $\begin{array}{l}\text { Antidoto, } \\
\text { Quemaduras }\end{array}$ \\
\hline Cerebro & & Cerebellum $3,22,11 /$ & Cerebellum 43 & $\begin{array}{l}\text { Como alimento en } \\
\text { fiebres, } \\
\text { Antiintlamatorio } \\
\end{array}$ \\
\hline $\begin{array}{l}\text { Cervo (Cuerno, } \\
\text { sangre, etc.) }\end{array}$ & & $\begin{array}{l}\text { Cervus } 4,22,3 / 4,27,1 \mathrm{Cl} \\
5,5,26,6,16 \mathrm{C} / 6,9,27 \\
\text { Cuerno: } 3,20,2 \\
\end{array}$ & $\begin{array}{l}\text { Cenus } 13,60,122, \\
\text { 141, 163, 238, 262, } \\
\text { 270; Pulmón: } 76 \\
\end{array}$ & $\begin{array}{l}\text { Estimulane, En el } \\
\text { cólico, Emoliente, } \\
\text { Analgésico dental }\end{array}$ \\
\hline Cocodrilo (Testiculo) & & & Cocodrilo testiculum 14 & En epilepsia \\
\hline $\begin{array}{l}\text { Cola (de huesos, } \\
\text { cuemos, etc.) }\end{array}$ & & $\begin{array}{l}\text { Gluten } 5,2 / 8,5,2 / \text {; De } \\
\text { Toro: } 5,5,2\end{array}$ & Gluten de toro 254 & $\begin{array}{l}\text { Vulnerario, En } \\
\text { sarna, Detersivo }\end{array}$ \\
\hline Cola de Pescado & $\begin{array}{l}\text { Cola hecha con } \\
\text { restos de pescado }\end{array}$ & $\begin{array}{l}\text { Icthyocola } 5,2 / 5,19,7 / \\
5,19,8 /\end{array}$ & - & $\begin{array}{l}\text { Emoliente, } \\
\text { Vulnerario }\end{array}$ \\
\hline Conchas marinas & & - & $\begin{array}{l}\text { Concha 104, 122, } 191 \\
233\end{array}$ & $\begin{array}{l}\text { Antïnnilamatorio, } \\
\text { Antidoto, } \\
\text { En el cólico }\end{array}$ \\
\hline Coral & & Corallium 5,8 I & - & Cáustico \\
\hline Cordero Caldo, sangre & & & $185,189,197$ & Antidoto \\
\hline Cuerno $\{$ Qu emado\} & & $\begin{array}{l}\text { Cornu combusto } 3,20,1 / \\
5,22,2 / 5,24,41\end{array}$ & $\begin{array}{l}\text { Cornu combusto (ciervo) } \\
122\end{array}$ & $\begin{array}{l}\text { Corrosivo suave, } \\
\text { Analgésico, } \\
\text { En el cólico } \\
\end{array}$ \\
\hline Escorpión & & Scorpio 5,27,5/ & - & $\begin{array}{l}\text { Antidoto contra él } \\
\text { mismo }\end{array}$ \\
\hline Esponia & & $\begin{array}{l}\text { Spongia 2,33,2/5,2 } \\
5,28,12 \mathrm{H} / 5,28,12 \mathrm{~N} /\end{array}$ & $\begin{array}{l}\text { Spongea 43, 46, } 158 \\
205\end{array}$ & $\begin{array}{l}\text { Repercusivo, } \\
\text { Emoliente, } \\
\text { Vehiculo } \\
\end{array}$ \\
\hline Gallina (Grasa) & & Pullo gallinaceo $4,13,4$ i & Gallinae adeps 39, 185 & $\begin{array}{l}\text { Peripleumonia, } \\
\text { Antidoto, } \\
\text { Analgésico (oído) }\end{array}$ \\
\hline Ganso (Sangre) & & & $\begin{array}{l}\text { Anseris masculi sanguine } \\
177\end{array}$ & Antidoto \\
\hline Gato & & Sebum 2,33,5/ & & Calefacciente \\
\hline $\begin{array}{l}\text { Gladiador (Sangre, } \\
\text { cuchillo, higado) }\end{array}$ & $\begin{array}{l}\text { Su sangre se } \\
\text { consideraba muy } \\
\text { pura }\end{array}$ & $\begin{array}{l}\text { Gladiator (sanguis) } \\
3,23,71\end{array}$ & Gladiator (eicur) 17 & En Epilepsia \\
\hline
\end{tabular}


FÁRMACOS ORIGEN ANIMAL (Continuación)

\begin{tabular}{|c|c|c|c|c|}
\hline Español & Composición & En Celso & En Escribonio & Indicaciones \\
\hline Golondrina (Cenizas) & & \begin{tabular}{|l|} 
Hirundinis sanguinis \\
$6,6,39 / 5,5 /$ \\
Hirundinis carbo: $4,7,5 /$ \\
\end{tabular} & Hirundinis carbo 70 & $\begin{array}{l}\text { Cicatrizante (ojos), } \\
\text { Antiintlamatorio, } \\
\text { Detersivo } \\
\end{array}$ \\
\hline $\begin{array}{l}\text { Grasa (Ternera, } \\
\text { gallinas, etc.) }\end{array}$ & & $\begin{array}{l}\text { Adeps } 5,3 / 5,5,2 / 5,15 / \\
\text { etc. }\end{array}$ & Adeps (grasa vieja) 267 & $\begin{array}{l}\text { Madurativo, } \\
\text { Detersivo, } \\
\text { Emoliente }\end{array}$ \\
\hline $\begin{array}{l}\text { Heces (cabra, lagarto, } \\
\text { etc.) }\end{array}$ & & $\begin{array}{l}\text { Stercum } 5,8 / 5,19,28 / \\
5,27,8 / 6,18,5 !\end{array}$ & - & $\begin{array}{l}\text { Cáustico, } \\
\text { Atractivo, } \\
\text { Antídoto mordeduras }\end{array}$ \\
\hline $\begin{array}{l}\text { Hiel (de toro, hiena, } \\
\text { etc) }\end{array}$ & & $\begin{array}{l}\text { Fel } 4,7,3 / 5,5,2 i 5,6,2] \\
5,7 !\end{array}$ & Fel $68,70,230$ & $\begin{array}{l}\text { Emoliente, } \\
\text { Erosivo, Detersivo }\end{array}$ \\
\hline Hiena (piel, hiel) & & - & Hyaena 38,172 & $\begin{array}{l}\text { Antidoto (rabia), } \\
\text { En catarata }\end{array}$ \\
\hline Higado & & $\begin{array}{l}\text { Cabra: } 6,6,38 ; \text { De } \\
\text { paloma: } 4,15,3\end{array}$ & - & $\begin{array}{l}\text { Enf. hepática, } \\
\text { Colirio en Ceguera } \\
\text { nocturna } \\
\end{array}$ \\
\hline Huevc yema & & $\begin{array}{l}\text { Crudus vitellus } 5,52 / \\
5,11 / 5,15 / 5,19,28 / \mathrm{etc} .\end{array}$ & Crudus vitellus 115,121 & $\begin{array}{l}\text { Detersivo, } \\
\text { Antinflamatorio, } \\
\text { Emoliente } \\
\end{array}$ \\
\hline Huevo, clara de & & $\begin{array}{l}\text { Ovi album } 4,27,1 \mathrm{D} / 5,2 / \\
5,13 / 6,6,1 \mathrm{~K} / 6,6,8 \mathrm{~B} \\
8,10,7 \mathrm{M} /\end{array}$ & - & $\begin{array}{l}\text { Antiinflamatorio, } \\
\text { Vutneranio, } \\
\text { En oftalmias }\end{array}$ \\
\hline Laganto (Heces) & & Lacertus 5,5 & - & Detersivo \\
\hline Lana & & \begin{tabular}{|l|} 
Lana $5,2 / 5,26,301$ \\
$7,16,5 / 7,29,10 / 8,4,18 /$ \\
$8,30,10 / 8,11,7 / 8,15,7$ \\
\end{tabular} & Lana 158,161 & \begin{tabular}{|l} 
Antiuntlamatorio, \\
Emoliente, \\
Vulnerario \\
\end{tabular} \\
\hline Lana lavada & & $\begin{array}{l}\text { Lana mol lis } 7,26,5 \mathrm{C} / \\
7,30,1 / 8,6,2 / 8.9,10 /\end{array}$ & - & En Apósitos \\
\hline Lana sulfurada & $\begin{array}{l}\text { Lana impregnada } \\
\text { de azufre }\end{array}$ & $\begin{array}{l}\text { Lana sulphurata } 4,12,4 \text { / } \\
4,13,3\end{array}$ & Lana sulphurata 43 & \begin{tabular}{|l} 
Vulnerario, \\
Antinnilamatorio \\
\end{tabular} \\
\hline Lana, grasa de & $\begin{array}{l}\text { Grasa de lana } \\
\text { (lanolina) }\end{array}$ & $\begin{array}{l}\text { Oesypum } 5,19,10 \\
6,18,7 \mathrm{~A} 6,18,8 \mathrm{~A}\end{array}$ & Oesypum 270 & $\begin{array}{l}\text { Antiinflamatorio, } \\
\text { Madurativo, } \\
\text { Analgésico } \\
\end{array}$ \\
\hline $\begin{array}{l}\text { Leche (cabra, vaca, } \\
\text { mujer, oveja, burra) }\end{array}$ & & \begin{tabular}{|l} 
Lac $4,9,3 / 4,19,2 /$ \\
$4,22,3 / 4,27,2 / 4,31,9$ \\
$5,815,11 /$ elc. \\
\end{tabular} & Lac $132,135,158$ & \begin{tabular}{|l} 
Cáustico, \\
Dispersante, \\
Antiunflamalorio \\
\end{tabular} \\
\hline León (grasa de) & & Adeps leonina $5,21,71$ & - & $\begin{array}{l}\text { En esterilidad } \\
\text { temenina }\end{array}$ \\
\hline Liebre (Cuajo) & & $\begin{array}{l}\text { Coaguíum leporinum } \\
5,5,2\end{array}$ & $\begin{array}{l}\text { Leporis coagulum } 175, \\
187,197\end{array}$ & \begin{tabular}{|l} 
Detersivo, \\
Antidoto, \\
Antinflamatorio \\
\end{tabular} \\
\hline Liebre Marina & $\begin{array}{l}\text { Cyclopterus } \\
\text { lumpus (un } \\
\text { gasterópodo) } \\
\end{array}$ & - & Marini leporis 80, 186 & $\begin{array}{l}\text { Antiinflamatorio. } \\
\text { Toxico }\end{array}$ \\
\hline Lirón (grasa de) & & -- & Giliris pingue 39 & Analgésico (otitis) \\
\hline Lobo (higado de) & & - & Lupi iecur 123 & $\begin{array}{l}\text { En enfermedades } \\
\text { hepáticas }\end{array}$ \\
\hline
\end{tabular}


FÁRMACOS ORIGEN ANIMAL (Continuación)

\begin{tabular}{|c|c|c|c|c|}
\hline Español & Composición & En Celso & En Escribonio & Indicaciones \\
\hline $\begin{array}{l}\text { Lombriz de tierra } \\
\text { (hervida) }\end{array}$ & & Lumbrix $6,7,1 \mathrm{D}$ & - & En otalgias \\
\hline Macho cabrio (sangre) & & Hircus $4,16,4 /$ & Hircus 177 & $\begin{array}{l}\text { Atractivo, En } \\
\text { enfermedades del } \\
\text { bazo, Antidoto }\end{array}$ \\
\hline Manteca & & $\begin{array}{l}\text { Buturum 3,22,13/ } \\
4,25,2 / 5,14 / 5,15 / \\
5,19,10 / 5,21,4 / 5,24,3 /\end{array}$ & Butyrum 43, 238 & $\begin{array}{l}\text { Madurativo, } \\
\text { Granulativo, } \\
\text { Emoliente }\end{array}$ \\
\hline Marfil & & Ebur $5,5,21$ & Eboreus 16,83 & $\begin{array}{l}\text { Detersivo, } \\
\text { Hemostatico, } \\
\text { En epilepsia }\end{array}$ \\
\hline $\begin{array}{l}\text { Mèdula ósea (de buey. } \\
\text { (ternera, etc.) }\end{array}$ & & $\begin{array}{l}\text { Medula } 5,15 / 5,19,20 / \\
5,24,3 i\end{array}$ & - & $\begin{array}{l}\text { Emoliente, } \\
\text { Detersivo }\end{array}$ \\
\hline Mena & $\begin{array}{l}\text { Pez } \\
\text { acantopterigio }\end{array}$ & - & Mena 71 & Cáustico \\
\hline $\begin{array}{l}\text { Miriapodos } \\
\text { ¿Cochinilla? }\end{array}$ & $\begin{array}{l}\text { "Bestiola } \\
\text { muitorum pedum" }\end{array}$ & - & Polipodes 39 & En otitis \\
\hline Mono (Heces) & & Simini stercoris $5,18,15$ & - & Emoliente \\
\hline Mulo (Cuajo) & & & Coagulum hinnuli: 188 & Antidoto \\
\hline Múrice o Pưrpura & $\begin{array}{l}\text { Murex brandarius } \\
O M . \text { trunculus }\end{array}$ & $\begin{array}{l}\text { Murex } 2,14,3 / 2,28,2 \\
5,18,21 / 5,28,2\end{array}$ & Murex. Purpura 104 & $\begin{array}{l}\text { Astringente intest.. } \\
\text { Emoliente } \\
\text { En gastritis }\end{array}$ \\
\hline Oca (huevos, grasa) & & - & $\begin{array}{l}\text { Anser } 185,189,238 \text {, } \\
271\end{array}$ & $\begin{array}{l}\text { Antidoto, } \\
\text { Cicatrizante }\end{array}$ \\
\hline Orina de niño & & $\begin{array}{l}\text { Urina impuberis pueri } \\
5,22,4 /\end{array}$ & - & Corrosivo suave \\
\hline Oveja (heces) & & Ovillum stercus $5,8 /$ & - & Cáustico \\
\hline Paloma (heces) & & $\begin{array}{l}\text { Columba stercus } 5,12 i \\
5,19,28 /\end{array}$ & - & $\begin{array}{l}\text { Epispástico, } \\
\text { Atractivo }\end{array}$ \\
\hline Palomo (Sangre de) & $\begin{array}{l}\text { Columba } \\
\text { palumbus }\end{array}$ & Palumbus 5,5/5,6,39/ & Palumbus 16 & $\begin{array}{l}\text { Epilepsia, } \\
\text { Detersivo, } \\
\text { Traumat. oculares }\end{array}$ \\
\hline Pastinaca $\{$ Pez) & & $\begin{array}{l}\text { Pastinaca, Trygona } \\
5,27,10 / 6,9,6\end{array}$ & - & $\begin{array}{l}\text { Corrosivo (dental), } \\
\text { Antidoto } \\
\text { mord. serp. }\end{array}$ \\
\hline Pelo quemado & & Pilus $3,20,2$ & - & Estornutatorio \\
\hline $\begin{array}{l}\text { Perro negro (sangre, } \\
\text { grasa, piel) }\end{array}$ & & - & Canis nigrum 161,175 & $\begin{array}{l}\text { Antigotoso, } \\
\text { Atractivo }\end{array}$ \\
\hline $\begin{array}{l}\text { Pollo (cortado por la } \\
\text { mitad) }\end{array}$ & & $\begin{array}{l}\text { Gallinaceum putlum } \\
5,27,3 \mathrm{D} \\
\end{array}$ & - & $\begin{array}{l}\text { Atractivo veneno } \\
\text { serpiente }\end{array}$ \\
\hline Propoleo & $\begin{array}{l}\text { Cera con la que } \\
\text { tapan los panales } \\
\text { las abejas }\end{array}$ & $\begin{array}{l}\text { Propolis } 5,4 / 5,12 / \\
5,19,15 / 5,28,11 \mathrm{Cl}\end{array}$ & $\begin{array}{l}\text { Propolis } 82,209,214, \\
262\end{array}$ & $\begin{array}{l}\text { Apertivo, } \\
\text { Epispástico, } \\
\text { Emoliente }\end{array}$ \\
\hline Queso & & Caseum 2,20,1/ & Caseum 158 & $\begin{array}{l}\text { Laxante, } \\
\text { Antigutoso }\end{array}$ \\
\hline
\end{tabular}


FÁRMACOS ORIGEN ANIMAL (Continuación)

\begin{tabular}{|c|c|c|c|c|}
\hline Español & Composicion & En Celso & En Escribonio & Indicaciones \\
\hline Queso envejecido & & $\begin{array}{l}\text { Caseum vetustum } \\
2,30,2\end{array}$ & Veleratum caseum 140 & $\begin{array}{l}\text { Vermifugo, } \\
\text { Astringente intest. }\end{array}$ \\
\hline Salamandra & $\begin{array}{l}\text { Salamandra } \\
\text { maculata }\end{array}$ & Salamandra 5,7/5,8/ & Salamandra 187 & $\begin{array}{l}\text { Erosivo, } \\
\text { Cáustico }\end{array}$ \\
\hline Salamanquesa & $\begin{array}{l}\text { Stellio vulgaris o } \\
\text { Lacerto gecko }\end{array}$ & - & Stellio 164 & $\begin{array}{l}\text { Evita picadura de } \\
\text { escorpión }\end{array}$ \\
\hline Sanguijuela & & Sanguiruja $5,27,12 \mathrm{C} /$ & Hirudo o Sanguiruja 199 & Tóxico \\
\hline $\begin{array}{l}\text { Sebo (de toro, buey, } \\
\text { ternera, etc.) }\end{array}$ & & $\begin{array}{l}\text { Sebum } 5,3 / 5,5,2 / \text { y } 12 \\
\text { más }\end{array}$ & - & $\begin{array}{l}\text { Madurativo, } \\
\text { Detersivo, } \\
\text { Emoliente }\end{array}$ \\
\hline Tela de araña & & Etiam aranea 5,2 & - & Hemostático \\
\hline $\begin{array}{l}\text { Ternero (Grasa, } \\
\text { Médula) }\end{array}$ & & & $\begin{array}{l}\text { Medulae vitulina 201, } \\
238.255\end{array}$ & $\begin{array}{l}\text { Vulnerario, } \\
\text { Analgésico }\end{array}$ \\
\hline Tinta de calamar & & $\begin{array}{l}\text { Atramentum sepiarum } \\
2,29,2\end{array}$ & - & Laxante \\
\hline Toro & & $\begin{array}{l}\text { Taurus } 4,27,16 / 5,18,5 / \\
5,18,23 / 5,18,27 / \\
5,19,9 / 5,19,11 /\end{array}$ & $\begin{array}{l}\text { Taurus } 196,202,211 \\
254,260,262,263\end{array}$ & $\begin{array}{l}\text { Emoliente, } \\
\text { Madurativo, } \\
\text { Analgesico }\end{array}$ \\
\hline Torpedo (Pez) & Raia Torpedo & - & Torpedo $11,99,162$ & $\begin{array}{l}\text { Antigotoso, } \\
\text { Analgésico, } \\
\text { (cefaleas) }\end{array}$ \\
\hline $\begin{array}{l}\text { Tortuga macho (sangre } \\
\text { de) }\end{array}$ & & - & $\begin{array}{l}\text { Sanguis testudines } \\
\text { masculae } 16,177\end{array}$ & $\begin{array}{l}\text { En epilepsia, } \\
\text { Antidoto }\end{array}$ \\
\hline $\begin{array}{l}\text { Zorro (cenizas de } \\
\text { pulmón, Higado de) }\end{array}$ & & $\begin{array}{l}\text { Pulmo 4,8,4i; } \\
\text { lecur: } 4,18,4\end{array}$ & Pumo vulpi 76 & Antidisneico \\
\hline
\end{tabular}

